\title{
EL DESTINO DE LOS NIÑOS DE LA INCLUSA DE PONTEVEDRA, 1872-1903 ${ }^{1}$
}

\section{THE DESTINATION OF THE CHILDREN OF THE FOUNDLING OF PONTEVEDRA, 1872-1903.}

\author{
ANA MARÍA RODRÍGUEZ MARTÍN
}

\begin{abstract}
Resumen
Se estudia el destino que tuvieron los niños ingresados en la Inclusa de Pontevedra durante el período 1872-1903: la convivencia con sus nodrizas, la recuperación por parte de sus padres, el traslado al Hospicio, los prohijamiento y, en muchas ocasiones, la muerte prematura. Se analizan las características de las personas relacionadas con los asilados, ya fueran sus nodrizas, sus madres o sus prohijantes. Por último, se presenta la imagen pública de la Inclusa y sus acogidos, y los problemas de identidad de estas personas.
\end{abstract}

\section{Palabras clave}

Inclusa, Pontevedra, siglo XIX, expósitos, nodrizas, naturalización, legitimación prohijamiento, Hospicio, mortalidad de expósitos.

\begin{abstract}
This article studies what happened to the children admitted at the Pontevedra Foundling Hospital from 1872 to 1903: children' relationship with their wet-nurses, parents recovery of their children, admission at he Foundling Hospital, adoptions and, very often, premature deth.

People relating to the children in the institution, such as wet-nurses, mothers or fostered mothers, are studied. Admission practices and the public views of the foundling hospital are commente.
\end{abstract}

\section{Keywords}

Foundling Hospital, Pontevedra, 19 ${ }^{\text {th }}$ century, foundling, wet-nurses, naturalization, legitimaze, adoption, poorhouse, mortality of foundling.

\footnotetext{
${ }^{1}$ Entregado a la revista el 26 de septiembre de 2006.
} 


\section{INTRODUCCIÓN}

El destino de los niños acogidos en la Inclusa de Pontevedra es el objeto principal de este estudio. En él analizaremos en profundidad la mortalidad que presentaba la Institución y, sobre todo, aspectos no tratados hasta ahora, como las recuperaciones de los asilados por parte de sus madres, las características de estas mujeres, los prohijamientos y el traslado de los expósitos al Hospicio Provincial, además del destino de los niños supervivientes a todos estos procesos. El marco espacial de este trabajo es Pontevedra y su provincia, que era la zona atendida por la Institución, y la época que tenemos en cuenta es la de 1872, año de creación de la Inclusa, a 1903.

La documentación referida a la Inclusa que estudiamos está depositada en el Archivo Histórico de la Diputación Provincial de Pontevedra. El núcleo central son los libros de matrícula o de registro de entrada de los niños, que era donde se anotaban todas las circunstancias y la trayectoria vital de los asilados, desde el momento de su ingreso hasta que fallecían o dejaban de estar tutelado por la Inclusa. Estos libros se completan con los legajos que contienen las partidas de bautismo y de defunción de los acogidos, así como sus hojas de lactancia, que son unos documentos en los que se apuntaban las características de las amas, los salarios cobrados y el estado del menor que cuidaban. Además, contamos con los expedientes personales de cada niño. En ellos constaba toda la documentación y la correspondencia oficial a él referida pero, por desgracia, no están completos y lo mismo ocurre con los expedientes que se abrían por cada naturalización, legitimación o prohijamiento. Por último, el libro de Actas de Sesiones de la Comisión de Diputados encargada de la Inclusa, que recoge los acuerdos de dichas reuniones de 1878 a 1925, proporciona mucha información que completa la aportada por la documentación ya citada.

\section{LA INCLUSA DE PONTEVEDRA.}

El Reglamento de 1852, que desarrollaba la Ley de Beneficencia de 1849, establecía la existencia de una casa de maternidad y otra de expósitos en cada capital de provincia ${ }^{2}$. La Inclusa de Pontevedra nació el uno de julio de $1872^{3}$,

\footnotetext{
${ }^{2}$ Reglamento de fecha 14-5-1852 para la ejecución de la Ley de Beneficencia de 20-6-1849, art. 6. HERNÁNDEZ IGLESIAS, Fermín. Tratado práctico de la beneficencia particular, Madrid, 1874, pag. 21.

${ }^{3}$ GARNELO MARIÑAS, Elena. "La Inclusa provincial de Pontevedra, 1872-1894", en Pontevedra. Revista de Estudios Provinciales, Pontevedra, nº 4, 1988, pp. 144-152.
} 
con veinte años de retraso sobre lo establecido legalmente. Antes de 1872, los expósitos de Pontevedra eran enviados a la Inclusa del Gran Hospital de Santiago ${ }^{4}$.

La dirección de la Inclusa de Pontevedra estuvo, desde su creación hasta 1878, en manos de la Asociación de Señoras de la Casa Hospicio, aunque legalmente correspondía a la Diputación Provincial el control de los establecimientos benéficos de la Provincia. Este caso no era excepcional, pues la presencia femenina en la beneficencia era general en toda España ${ }^{5}$. Las señoras que se dedicaban a la beneficencia pertenecían a la aristocracia o a la burguesía, o bien eran familiares de hombres dedicados a profesiones liberales ${ }^{6}$. Las encontramos en las juntas de damas de las inclusas de Barcelona, y Madrid, y en la Casa Cuna de Sevilla ${ }^{7}$. Estas mujeres solían ser muy activas en la búsqueda de fondos. La Asociación de Señoras de la Casa Hospicio de Pontevedra realizaba diversas actividades como bailes de piñatas, conciertos, funciones de teatro, rifas de dulces, de cortes de pantalones, y hasta de un cerdo ${ }^{8}$. A partir de 1878, esta Asociación abandonó la dirección de la Inclusa de Pontevedra y la Comisión de Diputados provinciales encargada de este establecimiento benéfico tomó el mando, aunque se encargó casi únicamente de las cuestiones económicas. Sus reuniones fueron escasísimas, sobre todo a partir de 1880, pues sólo se celebraron cada año entre dos y cinco sesiones $^{9}$. Del funcionamiento diario de la Inclusa y del control de todo su per-

\footnotetext{
${ }^{4}$ Archivo Histórico de la Diputación de Pontevedra, a partir de ahora, AHDP, Hospitales, leg. 435, 2.164 y 2.165. Sección Beneficencia, leg. 5. Serie 11/197, leg. 993.

5 "Miscelánea", en Revista de Beneficencia, Madrid, n 12, 4-7-1887, pag. 3. PERINAT, Adolfo y MARRADES, María Isabel. Mujer, prensa y sociedad en España, 1900-1939, Centro de Investigaciones Sociológicas, Madrid, 1980, pag. 172. El Consultor. Nueva guía de Barcelona, Barcelona, 1857, pp. 421 y 422. LAFFITE, María (duquesa de Campo Alange). La mujer en España. Cien años de su historia, 1860-1960, Aguilar, Madrid, 1963, pag. 142.

${ }^{6}$ AHDP, Hospitales, leg. 2.165. ARENAL, Concepción. La beneficencia, la filantropía y la caridad, Madrid, 1861, pag. 113. GÓMEZ-FERRER MORANT, Guadalupe. "La imagen de la mujer en la novela de la Restauración: ocio social y trabajo doméstico", en AA.VV. Mujer y sociedad en España, 1700-1976, Ministerio de Cultura, Madrid, 1986, pag. 86. Manual de Beneficencia, Madrid, 1931, pag. 117. DEMERSON, Paula de. "Catálogo de las socias de honor y mérito de la Junta de Damas Matritense", en Anales del Instituto de Estudios matritense, vol. VII, Madrid, 1971, pp. 269-274.

7 GUARDIA, Carmen de la. "El gran despertar. Románticas y reformistas en Estados Unidos y España", en Historia Social, Valencia, no 31, 1998, pp. 22 y 23. VIDAL GALACHE, Florentina y Benicia. "Porque Usía es condesa", en Espacio, tiempo y forma, serie V, Madrid, n 11, 1988, pp. 5772. ÁLVAREZ SANTALÓ, León Carlos. Marginación social y mentalidad en Andalucía Occidental: Expósitos en Sevilla (1613-1910), Junta de Andalucía, Sevilla, 1980, pp. 37 y 38. ALBÓ MARTÍ, Ramón. Barcelona caritativa, benéfica y social, Barcelona, 1914, vol. II, pp. 43.

${ }^{8}$ AHDP, Hospitales, leg. 2.165.

${ }^{9}$ AHDP, Fondo Especial, a partir de ahora, F.E., n 15 , libro no 15.168.
} 
sonal, incluidas las nodrizas internas, se ocupaban las Hermanas de la Caridad de San Vicente de Paúl. ${ }^{10}$

Los niños ingresados en la Inclusa de Pontevedra no eran solamente hijos de padres desconocidos, sino también hijos naturales y niños legítimos desvalidos. Todos ellos entraban en este centro benéfico después de haber sido expuestos en el torno o fuera de él, o bien después de haber sido entregados personalmente a la Hermana tornera.

En la Inclusa de Pontevedra, a lo largo del período 1872-1903, y al contrario de lo que ocurrió en el resto de las inclusas españolas ${ }^{11}$, aumentó el porcentaje de niños que entraban por el torno así como el número de ingresos totales, como podemos ver en el cuadro que sigue, el $n^{\circ} 1$. La explicación creemos que radica en que mientras que la tasa de natalidad descendió en el conjunto de España ${ }^{12}$, en Pontevedra aumentó de forma considerable ${ }^{13}$. Además, el porcentaje de hijos ilegítimos respecto a los nacidos era muy alto en esta provincia y, en general, en toda Gali$\mathrm{cia}^{14}$, y eran precisamente estos niños los que tenían más probabilidades de ser dejados en las inclusas, tal como señalan los estudiosos del tema de los expósitos en el siglo XIX y principios del $\mathrm{XX}^{15}$.

${ }^{10}$ FARIÑA JAMARDO, Xosé y PEREIRA FIGUEROA, Miguel. A Deputación de Pontevedra, 1836-1986, Diputación de Pontevedra, Pontevedra, 1986, pp. 354 y 366-8.

${ }^{11}$ PÉREZ GARCÍA, José Manuel. "La mortalidad infantil en la Galicia del siglo XIX. El ejemplo de los expósitos del Hospital de los Reyes Católicos de Santiago", en Estudios Compostelanos, Santiago de Compostela, $\mathrm{n}^{\circ}$ 4, 1976, pp. 174-5. URIBE ETXEBARRÍA, Arántzazu. Marginalidad protegida: mujeres y niños abandonados en Navarra, 1890-1930, Universidad del País Vasco, Bilbao, 1996, pag. 174. VALVERDES LAMSFUS, Lola. Entre el deshonor y la miseria. Infancia abandonada en Guipúzcoa y Navarra. Siglos XVIII y XIX. Universidad del País Vasco, Bilbao, 1996, pp. 59-99. ÁLVAREZ SANTALÓ, León Carlos. Op. cit., pp. 45-100. GUTIÉRREZ SÁNCHEZ, Mercedes. "Crisis social y asistencia pública en el último cuarto del siglo XIX”, en AA.VV., Historia de la acción social pública en España. Beneficencia y previsión, Ministerio de Trabajo y Seguridad Social, Madrid, 1990, pag. 288. JUNCEDA AVELLO, Enrique. Historia del Real Hospicio y Hospital Real de la Ciudad de Oviedo, Instituto de Estudios Asturianos, Oviedo, 1984, pp. 227-280. BORRÁS LLOP, José María. Historia de la infancia en la España contemporánea, 1834-1936, Ministerio de Trabajo y Asuntos Sociales, Madrid, 1996, pag. 140. Archivo Histórico de la Diputación de Barcelona, a partir de ahora, AHDB, leg. j-3.061 al j-3.112.

12 NADAL, Jordi. La población española, Ariel, Barcelona, 1984, pag. 145. Reseña geográfica y estadística de España, Madrid, 1888, pp. 13 y 14.

13 PÉREZ FARIÑA, María Luisa. La ciudad de Pontevedra. Evolución histórica y demográfica, Universidad de Santiago de Compostela, Santiago de Compostela, 1985, pp. 60-61.

${ }^{14}$ AHDP, F.E. no 15, leg. 982 y 983. BARREIRO FERNÁNDEZ, Xosé Ramón. Historia de Galicia, Gamma, La Coruña, 1984, vol. IV, pp. 165-167.

15 ÁLVAREZ SANTALÓ, León Carlos. Op. cit., pp. 192-195. VALVERDE LAMSFUS, Lola. Op. cit., pp. 77-81. 
CUADRO No 1: Ingresos anuales en la Inclusa de Pontevedra, 1872-1903 ${ }^{16}$.

\begin{tabular}{lcl} 
Años & Total ingresos & \% de entrados por el torno \\
\hline & & \\
1872 & 21 & 57,1 \\
1873 & 51 & 35,3 \\
1878 & 69 & 66 \\
1883 & 65 & 87,7 \\
1888 & 92 & 71,7 \\
1893 & 88 & 78,5 \\
1898 & 100 & 87 \\
1903 & 114 & 92,1 \\
\hline
\end{tabular}

Los pasos que se seguían en la Inclusa de Pontevedra para efectuar el ingreso de los acogidos eran prácticamente los mismos que en otras inclusas gallegas ${ }^{17}$. Primero, se bautizaba al recién entrado y luego se registraba en el libro de matrícula. Posteriormente, y tras un período de tiempo que variaba de días a semanas, los niños que eran entregados a amas de lactancia o nodrizas, o a amas de destete si no eran lactantes. A los siete años, muchos acogidos se quedaban con sus amas y otros eran retornados a la Inclusa y de allí eran trasladados al Hospicio Provincial.

\section{EL DESTINO DE LOS NIÑOS DE LA INCLUSA DE PONTEVEDRA}

En este apartado vamos a analizar qué destino esperaba a los niños ingresados en la Inclusa de Pontevedra. A muchos de ellos era la muerte. A los supervivientes, la continuación de la convivencia con sus amas y, en el caso de ser devueltos a la Institución, su traslado al Hospicio Provincial a los siete años. Algunos expósitos fueron recogidos por sus madres y otros, muy pocos, fueron prohijados.

\subsection{La convivencia con las nodrizas}

En la vida de los acogidos en las inclusas tenían un papel importantísimo las nodrizas o amas. Las internas eran las que se ocupaban de su lactancia cuando

\footnotetext{
${ }^{16}$ AHDP, F.E. $\mathrm{n}^{\circ} 15$, libros $\mathrm{n}^{\circ} 15.169$ al 15.172, 15.174, 15.176 al 15.178, y 15.180.

${ }^{17}$ Reglamento de la Casa de Maternidad y Espósitos de la Provincia de Lugo, Lugo, 1863, art. 1. Reglamento para el régimen y gobierno del Gran Hospital de Santiago y de la Casa de Expósitos anexa al mismo, La Coruña, 1881, art. 215-226 y 256-8. FERNÁNDEZ FERNÁNDEZ, José María. "La Casa Cuna de Mondoñedo", en Estudios Mindonienses, Ferrol, n 12, 1996, pag. 415. SÁNCHEZ YÁNEZ, Margarita. "Nenos expósitos de Ferrol", en Estudios Mindonienses, Ferrol, no 12, 1996, pp. 541-542.
} 
ingresaban en estas instituciones. Pasado un tiempo, otras nodrizas, las externas, eran las que se los llevaban consigo para amamantarlos y, cuando terminaba esta lactancia, y ya como amas de destete, para cuidarlos hasta que llegaran a la edad reglamentaria.

En la Inclusa de Pontevedra las nodrizas eran su piedra angular, pues de ellas dependía la supervivencia de los niños. Estas mujeres estaban muy mal pagadas y su sueldo no experimentó mejoras durante el período que nosotros analizamos. Además, durante algunos años ni siquiera lo recibieron con regularidad ${ }^{18}$.

La mayoría de las amas de la Inclusa vivían en zonas rurales, como podemos ver en el cuadro $\mathrm{n}^{\mathrm{o}} 2$, y sólo en casos contados en Pontevedra capital, aunque eran numerosas las que residían en el resto de este municipio y en los vecinos de Poio y Xeve. Otra gran parte vivía en municipios del interior de la Provincia, como Cerdedo, Campo, Cotobade y A Lama ${ }^{19}$. La explicación de esta distribución geográfica está en que sólo aceptaban lactar expósitos las mujeres de las zonas más pobres, las del interior, y las que no tenían la salida profesional del servicio doméstico o de un nodrizaje particular, que estaba mucho mejor pagado. Por estas mismas razones podemos ver que había muchas amas de la provincia de Lugo, y más concretamente de los municipios de Pantón y Carballedo.

CUADRO Nº 2: Residencia de las nodrizas contratadas anualmente por la Inclusa de Pontevedra, $1872-1903^{20}$.

Municipios de la provincia de Pontevedra Municipios de la

\begin{tabular}{lccc} 
Año & Pontevedra, Xeve y Poio & Resto de la Provincia & Provincia de Lugo \\
\hline & & & \\
1873 & 6 & 15 & 28 \\
1878 & 14 & 33 & 19 \\
1883 & 15 & 43 & 15 \\
1888 & 25 & 72 & - \\
1893 & 28 & 42 & 41 \\
1898 & 19 & 48 & 20 \\
1903 & 48 & 42 & 25 \\
& & 295 & 145 \\
\hline Total & 155 & 49,6 & 24,4 \\
\hline
\end{tabular}

${ }^{18}$ RODRÍGUEZ MARTíN, Ana María. "La Inclusa de Pontevedra, 1872-1903”, en Pontevedra. Revista de Estudios Provincias, Pontevedra, n 19, 2003, pp. 188-189.

${ }^{19}$ Idem, pp. 190-196.

${ }^{20}$ Ibidem. 
Los salarios bajos de las nodrizas eran generales en las inclusas españolas, lo que provocaba que se ofrecieran pocas mujeres a ejercer este oficio. Algunas amas tenían leche de mala calidad o no trataban a los niños a su cargo de forma correc$\mathrm{ta}^{21}$. La Inclusa de Lugo, para mejorar el comportamiento de las nodrizas, ofrecía premios e imponía castigos ${ }^{22}$. Pero, la realidad es que ninguno de estos establecimientos benéficos pudo garantizar unas amas idóneas para sus acogidos. Sin embargo, estas mujeres fueron las que llevaron el peso de las inclusas, puesto que un porcentaje altísimo de niños se quedaban con ellas cuando ya no cobraban de las diputaciones provinciales ${ }^{23}$. Es más, muchas nodrizas trataron con verdadero afecto y dedicación a los expósitos a su cargo, llegando en algunos casos a la abnegación.

También en la Inclusa de Pontevedra, el hecho de que fueran unidas la lactancia y la pobreza provocaba que algunas amas hicieran todo lo posible para cobrar o no perder el salario del Centro benéfico, aún a costa de la salud de los propios niños. Por ello, algunos acogidos tenían nodrizas débiles o enfermas, y con leche vieja o escasa y, además, se veían obligados a compartir su pobreza ${ }^{24}$. Muchos de ellos se quedaron con sus amas después de haber cumplido los siete años, por lo que seguramente les esperaba el trabajo precoz y la pobreza.

\subsection{La muerte}

En España, en la segunda mitad del siglo XIX, se produjo un descenso lento de la mortalidad de la población general debido en mayor medida a las mejoras en la higiene, la alimentación y la vivienda, que a los avances en la lucha contra las enfermedades infecciosas ${ }^{25}$. Frente a este descenso, el de la mortalidad infantil no fue una realidad hasta bien entrado el siglo XX, y más en España,

21 "La Casa de Maternidad”, El Liberal, Barcelona, no 952, 22-11-1903. GONZÁLEZ CANALEJO, Carmen. "Las nodrizas en Almería: ¿Oficio o rol biológico?”, en Actas del III Congreso de Historia de Andalucía, vol. II, Cajasur, Córdoba, 2001, pp. 337-340. VALVERDE LAMSFUS, Lola. Op. cit., pag. 181. JUNCEDA AVELLO, Enrique. Op. cit., pag. 94. ÁLVAREZ SANTALÓ , León Carlos. Op. cit., pp. 121-123.

${ }^{22}$ Reglamento de la Casa de Maternidad y Espósitos de la Provincia de Lugo, Lugo, 1863, art. 106.

${ }^{23}$ AHDP, F.E. no 2, leg. 993 y 940. Sesión de la Comisión de Diputados de la Inclusa de Pontevedra, 31-10-1879, F.E. no 15, libro no 15.168. AHDB, leg. j-3.017 y j-3.029. VALVERDE LAMSFUS, Lola. Op. cit., pp. 176-177.

24 RODRÍGUEZ MARTÍN, Ana María. “La Inclusa de Pontevedra....”, op. cit., pp. 197-198.

25 FERNÁNDEZ GARCÍA, Antonio. "La enfermedad como indicador social. Consideraciones metodológicas", en CASTILLO, Santiago (coord.). La Historia Social en España. Actualidad y perspectivas, Siglo XXI, Madrid, 1991. 
pues en la lucha contra la mortalidad infantil estaba retrasada respecto a Europa Occidental ${ }^{26}$.

En el cuadro que sigue, el número 2, podemos ver que en las inclusas también bajó la mortalidad de los acogidos. En la de Pontevedra ocurrió lo mismo, aunque la mortalidad siguió siendo alta e, incluso, en la mayoría de los años que consideramos fallecieron más de la mitad de los niños ingresados. Más concretamente, solamente en trece de esos años murieron menos del $50 \%$ de los entrados.

CUADRO N $\mathrm{N}^{\circ}$ : Tanto por mil de fallecidos sobre los ingresos en las Inclusas de Pontevedra, Oviedo, Barcelona y Madrid 1872-190327.

$\begin{array}{lcccc}\underline{\text { Años }} & \begin{array}{c}\text { Inclusa de } \\ \text { Pontevedra }\end{array} & \begin{array}{c}\text { Hospicio } \\ \text { de Oviedo }\end{array} & \begin{array}{c}\text { Casa de Maternidad y } \\ \text { Expósitos de Barcelona }\end{array} & \begin{array}{c}\text { Inclusa } \\ \text { de Madrid }\end{array} \\ 1873 & 588 & 626 & 830 & - \\ 1874 & 585 & 595 & 825 & - \\ 1875 & 596 & 648 & 817 & - \\ 1876 & 555 & 625 & 724 & - \\ 1877 & 487 & 614 & 715 & - \\ 1878 & 638 & 495 & 726 & - \\ 1879 & 611 & 447 & 719 & - \\ 1880 & 615 & 424 & 680 & 873 \\ 1881 & 580 & 472 & 649 & 744 \\ 1882 & 556 & 443 & 683 & 837 \\ 1883 & 615 & 553 & 679 & 578 \\ 1885 & 500 & 530 & 563 & 636 \\ 1886 & 424 & 439 & 552 & 726 \\ 1887 & 364 & 606 & 560 & 695 \\ 1888 & 369 & 486 & 545 & 704 \\ 1889 & 544 & 543 & 471 & 619 \\ 1890 & 565 & 555 & 493 & \end{array}$

${ }^{26}$ ULTECIA CARDONA, C. "Mortalidad de la primera infancia", en AA.VV. Cuatro siglos de acción social. De la beneficencia al bienestar social, Siglo XXI, Madrid, 1986, pp. 163-175. COMÍN, Jorge. El problema de las inclusas en España, Dirección General de Sanidad, Madrid, 1944, pp. 4-5. BOUSQUET, J. "Medios para combatir la mortalidad infantil", en Gaceta Médica Catalana, Barcelona, vol. XXVI, nº 616, 28-2-1903, pp. 111-112. FUENTES CABALLERO, M. Teresa. "Costumbres privadas e interés público. La lactancia materna en la literatura médica de divulgación. Barcelona, 1880-1890", en Cynamis, vol. 16, Granada, 1996, pp. 382-394.

${ }^{27}$ De algunos años referidos a la Inclusa de Madrid no disponemos de datos. AHDP, Fondo Especial $\mathrm{n}^{\circ}$ 15, libros $\mathrm{n}^{\circ}$ 15.169-15.202. AHDB, leg. j-3.061 al j-3.112. HAUSER, Philippe. Madrid bajo el punto de vista medico-social, vol. II, Madrid, 1902, pag. 543. GUTIÉRREZ SÁNCHEZ, Mercedes. Op. cit., pp. 187-88. JUNCEDA AVELLO, Enrique. Op. cit., pp. 277-280. 


\begin{tabular}{lcccc}
$\underline{\text { Años }}$ & $\begin{array}{c}\text { Inclusa de } \\
\text { Pontevedra }\end{array}$ & $\begin{array}{c}\text { Hospicio } \\
\text { de Oviedo }\end{array}$ & $\begin{array}{c}\text { Casa de Maternidad y } \\
\text { Expósitos de Barcelona }\end{array}$ & $\begin{array}{c}\text { Inclusa } \\
\text { de Madrid }\end{array}$ \\
1892 & 407 & 478 & 550 & - \\
1893 & 579 & 728 & 494 & - \\
1894 & 543 & 525 & 536 & 426 \\
1895 & 471 & 487 & 513 & 477 \\
1896 & 415 & 463 & 513 & 313 \\
1897 & 471 & 529 & 523 & 185 \\
1898 & 470 & 571 & 550 & 414 \\
1899 & 500 & 608 & 544 & - \\
1900 & 377 & 563 & 514 & - \\
1901 & 465 & 314 & 473 & - \\
1902 & 448 & 407 & 437 & - \\
1903 & 385 & 406 & 515 & - \\
\hline
\end{tabular}

Si observamos el cuadro anterior y comparamos la mortalidad de diversas inclusas, tanto de ciudades grandes, como Madrid y Barcelona, como de otras pequeñas, como Oviedo, veremos que la de la Inclusa de Pontevedra se sitúa en un término medio. Es más, en trece de los 31 años que examinamos presentó las tasas más bajas de los establecimientos benéficos que comparamos.

No hemos calculado los porcentajes de los acogidos fallecidos en los locales de la Inclusa de Pontevedra y los que residían con las amas externas porque hemos comprobado que estos datos no son significativos. Muchos niños ingresaban en la Institución ya en muy mal estado y, en algunos casos, con enfermedades que acabarían con ellos en poco tiempo, como la sífilis. Todos estos asilados ya no llegaban a tener una nodriza externa. Otros, cuando ya vivían en la casa de sus amas, eran devueltos cuando estaban enfermos y, por eso, morían en los locales del Centro benéfico. Esta práctica de las amas era común en todas las inclusas españolas ${ }^{28}$.

Respecto a la mortalidad infantil, es decir, el tramo de 0-1 año, la Inclusa de Pontevedra llegó en 1883 y 1893 a presentar una mortalidad de más del 50\% de los ingresados, aunque a lo largo del período que analizamos fue descendiendo suavemente la mortalidad y ya en la última década del siglo XIX y en los primeros años del siguiente siglo la bajada fue notable, como podemos ver en el cuadro que sigue, el $\mathrm{n}^{\circ} 3$. Si comparamos la mortalidad infantil de la Inclusa de Pontevedra con la que presentaba la Casa de Maternidad y Expósitos de Barce-

${ }^{28}$ AGUIRRE BARRIO, Julián. Mortalidad en la primera infancia, sus causas y medios de atenuarlas, Madrid, 1885, pag. 132. VALVERDE LAMSFUS, Lola. Op. cit., pag. 226. ÁLVAREZ SANTALÓ, León Carlos. Op. cit., pag. 180. 
lona y la Inclusa del Hospicio de Oviedo, veremos que la evolución global fue similar, aunque en la de Oviedo el descenso es visible sólo a partir de 1900 y en la de Barcelona es continuado y constante desde el primer año que consideramos, el de 1873.

La evolución de la mortalidad infantil en la Inclusa de Pontevedra corrió pareja a la que presentaban los niños no asilados en España ${ }^{29}$. Esta mortalidad descendió más rápidamente a partir de principios del siglo XX, debido a los progresos de la pediatría y la puericultura ${ }^{30}$. Sin embargo, la mortalidad de los expósitos era mayor que la de los menores no asilados. Esto era así incluso si establecemos la comparación entre los asilados y los niños residentes en las capitales, sobre todo en las más grandes, donde debido a la poca higiene personal y pública y a la insalubridad de las viviendas la mortalidad infantil era mayor ${ }^{31}$. Si tenemos en cuenta el año 1903, en Pontevedra capital la mortalidad infantil fue del 108 por mil, y en la Provincia, sin contar la capital, del 107 por mil. En ese mismo año, la mortalidad infantil de la Inclusa de Pontevedra fue del 246 por mil. Incluso, en el tramo de edad de 1-2 años, y en 1903, las diferencias subsistían.

${ }^{29}$ MORTALIDAD INFANTIL EN TANTO POR MIL EN ESPAÑA, 1870-1903.

\begin{tabular}{lcc} 
Años & Provincias & Capitales \\
\hline 1870 & 234,7 & - \\
$1881-86$ & 438 & - \\
1899 & - & 220 \\
1901 & 186 & 221 \\
1902 & 181 & 198 \\
1903 & 162 & 180 \\
\hline
\end{tabular}

Elaboración propia a partir de LÓPEZ TABOADA, J. La población de Galicia, 1860-1991, Fundación Caixa Galicia, A Coruña, 1996, pp. 76 y 81. Boletín mensual de estadística demográfica-sanitaria de la Península e islas adyacentes. Madrid, 1883, vol. II, pag. 57 y vol. III, pp. 57 y 115 . ARBELO, Antonio. La mortalidad de la infancia en España, 1901-1950, Dirección General de Sanidad, Madrid, 1962, pp. 262 y 308-311. GONZÁLEZ ÁLVAREZ, Baldomero. Tratado didáctico de enfermedades de los niños, Madrid, 1905, pp. 555 y 556.

${ }^{30}$ HEUBNER, O. "En el XIII Congreso Internacional de Medicina, París 2-9 agosto 1900", en La Medicina de los Niños, Barcelona, $\mathrm{n}^{\circ}$ 9, septiembre de 1900, pp. 267-277.

${ }^{31}$ DOPICO, Francisco. "Desarrollo económico-social y mortalidad infantil. Diferencias regionales, 1900-1950)", en Crisis, autonomías y desarrollo regional, IX reunión de estudios regionales, Universidad de Santiago de Compostela, Santiago de Compostela, 1985, pag. 361. MARTÍNEZ VARGAS, Andrés. "La protección a los niños", en La medicina de los Niños, Barcelona, n 2, febrero de 1900, pag. 15. 
CUADRO No 4: Mortalidad infantil, en tanto por mil, de las inclusas de Pontevedra, Oviedo y Barcelona, 1872-1903. ${ }^{32}$

\begin{tabular}{lccc} 
Años & $\begin{array}{c}\text { Inclusa de } \\
\text { Pontevedra }\end{array}$ & $\begin{array}{c}\text { Inclusa del Hospicio } \\
\text { de Oviedo }\end{array}$ & CMEB \\
\hline & & & 748 \\
1873 & 294 & 396 & 709 \\
1874 & 283 & 355 & 533 \\
1878 & 478 & 238 & 547 \\
1879 & 222 & 308 & 496 \\
1883 & 523 & 348 & 425 \\
1884 & 444 & 280 & 358 \\
1888 & 239 & 330 & 302 \\
1889 & 402 & 370 & 351 \\
1890 & 471 & 363 & 346 \\
1891 & 315 & 368 & 407 \\
1892 & 321 & 473 & 349 \\
1893 & 511 & 524 & 383 \\
1894 & 457 & 353 & 366 \\
1895 & 304 & 316 & 326 \\
1896 & 305 & 250 & 348 \\
1897 & 353 & 333 & 389 \\
1898 & 380 & 319 & 411 \\
1899 & 430 & 491 & 355 \\
1900 & - & 427 & 335 \\
1901 & 257 & 145 & 318 \\
1902 & 388 & 215 & 383 \\
1903 & 246 & 195 & \\
\hline & & & \\
& & &
\end{tabular}

La mortalidad de los expósitos era achacada, por parte de algunos médicos y directores de las inclusas, al mal estado en el que ingresaban en las instituciones benéficas y a las malas condiciones en las que sus madres habían pasado el embarazo y habían parido $^{33}$. Algunos tratadistas, incluso, añadían las enfermedades venéreas padecidas por estas mujeres que luego transmitían a sus hijos. Sin embargo, y ya en 1924, dos médicos de la Inclusa de Madrid, la más grande de España, desechaban todas estas circunstancias como factores determinantes en los fallecimientos de los acogidos ${ }^{34}$.

\footnotetext{
32 No contamos con los datos de 1900 de la mortalidad infantil en la Inclusa de Pontevedra. AHDP, F.E. $n^{\circ} 15$, libros $n^{\circ}$ 15.169-15.202. AHDB, leg. j-3.061 al j-3112. JUNCEDA AVELLO, Enrique. Op. cit., pp. 277-280.

${ }^{33}$ Informe del director de la Casa de Maternidad y Expósitos de Barcelona, 1903. AHDB, leg. j-3.022.

34 BRAVO FRÍAS, J. y ALONSO MUÑOYERRO, J. A. La transformación de las inclusas, Madrid, 1924, pp. 13-14.
} 
Las causas de la mortalidad en la Inclusa de Pontevedra eran las mismas que las del resto de inclusas españolas y francesas ${ }^{35}$. Se trataba, básicamente, de que los asilados eran alimentados y cuidados por amas que, dado el salario tan bajo que pagaban las inclusas, eran las peores del mercado. Además, los niños, antes de ser entregados a estas mujeres, permanecían durante un tiempo en unos locales que no reunían las debidas condiciones y que, además, no solían ser tan amplios como para evitar el hacinamiento o para facilitar el aislamiento de los que padecían enfermedades infecciosas ${ }^{36}$. En estas instalaciones los expósitos eran lactados por nodrizas internas, pero solían ser escasas, por lo que en ocasiones había que recurrir a la lactancia artificial. También recibían este mismo alimento los que tenían enfermedades contagiosas, entre ellas la sífilis. La lactancia artificial equivalía a una condena a muerte ${ }^{37}$. Todavía en 1917 los médicos de la Inclusa de Madrid calificaban la sala del biberón como "herodiada" y "antesala del Cielo"38.

A todas las causas ya citadas tenemos que añadirles que muchos niños, y al poco tiempo de nacer, hacían un viaje desde el lugar donde sus madres los habían parido o donde habían sido expuestos, a la inclusa de la capital de provincia. Desde allí volvían a hacer otro viaje hasta el pueblo o la aldea donde residiera su ama, con la que compartiría su pobreza y su vivienda. Por último, muchos expósitos entraban ya en las inclusas con enfermedades heredadas, como la sífilis, o bien estaban faltos de tiempo de gestación o presentaban problemas debido a que sus madres habían pasado el embarazo sin las debidas condiciones y habían parido sin la asistencia adecuada ${ }^{39}$. Además, algunos niños expuestos fuera del torno ingresaban des-

\footnotetext{
35 Actas del Congreso Médico Internacional de Sevilla, Sevilla, 1882, pp. 225-228. GRASSET, Vicente. "De los expósitos", Acta de la sesión literaria pública que el día 2 de enero de 1851 celebró la Academia Nacional de Medicina y Cirugía de Barcelona, Barcelona, 1851, pp. 31-36. LAPLAIGE, Danielle. Sans famille à París. Orphelins et enfants abandones de la Seine au XIX siècle, Centurión, París, 1989, pp. 53-59 y 62-3. BEAUVALET-BOUTOURYE, Scarlett. Naître à l'hôpital au XX siècle, editorial Belín, París, 1999, pp. 91-93. BROCHARD, M. La vérité sur les enfants trouvés, París, 1876, pp. 156-157. MONTIEL PASTOR, Josep. “De la creació fins a la Mancomunitat, 1853-1924”, en AA. VV. La Casa de Maternitat i Expòsits. Les Corts, Ayuntamiento y Diputación de Barcelona, Barcelona, 2004, pag. 46.

36 TOLOSA LATOUR, M. Medicina e higiene de los niños, Madrid, 1893, pag. 111.

${ }^{37}$ GÓMEZ SALVO, L. Las inclusas españolas. De sus defectos y del modo de corregirlas, Zaragoza, 1926, pag. 15 .

38 BRAVO FRÍAS, J. y ALONSO MUÑOYERRO, J.A. Op. Cit., pp. 18 y 19.

39 "Miscelánea", "Expósitos enfermos", "Miscelánea" y "Lactancia mercenaria", en Revista de Beneficencia, Madrid, $\mathrm{n}^{\circ}$ 2, 5, 16 y 18, respectivamente, de fechas 22-8-1887, 15-9-1887, 8-12-1887 y 22-12-1887, pp. 6, 3, 5 y 3, respectivamente. ARENAL, Concepción. "Pobres inocentes", en La Voz de la Caridad, de beneficencia y establecimientos penales, Madrid, $\mathrm{n}^{\circ}$ 31, 15-6-1871, pp. 97-100. RULL, Juan y CABOT, José. Estudio demográfico-médico del quinquenio de 1883 a 1887 de la Casa Provincial de Maternidad y Expósitos de Barcelona, Barcelona, 1889, pag. 17.
} 
pués de haber estado durante horas, sobre todo nocturnas, a la intemperie y sin alimento alguno ${ }^{40}$. Esta altísima mortalidad de las inclusas no escandalizaba ni asombraba a la sociedad porque también los hijos de los pobres morían en un gran porcentaje, siempre superior al que presentaban las clases acomodadas ${ }^{41}$.

En la Inclusa de Pontevedra se daban todas las circunstancias que acabamos de mencionar y que eran las causantes de la mortalidad de los expósitos. Algunos de ellos eran abandonados a las puertas de casas, generalmente por la noche. Las madres confiaban en que los lloros del niño despertarían a los dueños y éstos llevarían al recién nacido a la Inclusa. Aunque estos menores eran abandonados abrigados e, incluso, en lugares altos, como el alféizar de una ventana o en cestitas colgadas de clavos para no ser atacados por animales, la realidad es que este tipo de abandono suponía un riesgo para el niño. Aunque sólo un 15\% del total de ingresados en la Inclusa de Pontevedra en los años que consideramos fue expuesto de esta manera, creemos que es un porcentaje a tener en cuenta ${ }^{42}$.

Respecto a los locales ocupados por la Inclusa, el convento de Santa Clara y el del Santo Domingo, tenemos que señalar que no habían sido creados para acoger recién nacidos y no reunían las condiciones adecuadas. Por encima, como los salarios que pagaba la Diputación a las nodrizas externas eran tan bajos, pocas venían a coger expósitos, por lo que los niños estaban en unas instalaciones inadecuadas durante un tiempo demasiado prolongado, que variaba entre unos días y unas semanas e, incluso, podía llegar a dos meses ${ }^{43}$. Cuando las amas externas se los llevaban a sus aldeas, tenían los niños que hacer un viaje demasiado largo, puesto que ya hemos visto que sólo las nodrizas de las zonas más pobres y más alejadas de la Capital querían lactar a un inclusero.

\subsection{La recuperación por parte de los padres}

Los reglamentos de las inclusas, a mediados del siglo XIX, no citaban, o bien lo hacían de forma muy vaga, la posibilidad de recuperación de los expósitos por parte de sus padres ${ }^{44}$. Sin embargo, hacia finales de ese siglo, los reglamentos de estos

${ }^{40}$ LÓPEZ-CORDÓN CORTEZO, M ${ }^{a}$ Victoria. "La situación de la mujer a finales del Antiguo Régimen (1760-1860)", en AA.VV. Mujer y sociedad en España (1700-1975), Ministerio de Cultura, Madrid, 1986, pag. 16.

${ }^{41}$ FIGUEROLA, Laureano. Estadística de Barcelona en 1849. Reedición del Instituto de Estudios Fiscales, Madrid, 1968, pag. 119.

42 Los años que hemos considerado son 1872, 1873, 1878, 1883, 1888, 1893, 1898 y 1903. AHDP, F.E. $\mathrm{n}^{\mathrm{o}} 15$, libros $\mathrm{n}^{\mathrm{o}} 15.169,15.170$ al $14.172,15.174,15.176$ al 15.178 y 15.180 .

${ }^{43}$ AHDP. Idem.

${ }^{44}$ Reglamento para el régimen interior administrativo y económico del establecimiento provincial de Espósitos de Málaga y sus hijuelas, Málaga, 1858, art. 64 y 65. VALVERDE LAMSFUS. Op. cit., pp. 237 y 238. 
centros benéficos contemplaban las recuperaciones de asilados ${ }^{45}$ y establecían las formalidades necesarias para ello, que eran las mismas que ordenaba el Reglamento de Beneficencia de $1852^{46}$. Es decir, era necesario que las personas que quisieran hacerse cargo de sus hijos acogidos en las inclusas los naturalizaran o los legitimaran, y que abonasen el coste de la crianza durante el tiempo que hubieran estado asilados, aunque esto último podía evitarse si se presentaba una declaración de pobreza.

La entrega de los expósitos, una vez que habían sido naturalizados o legitimados, no era automática y podía suspenderse por mala conducta de los padres, tal como establecía el Reglamento de Beneficencia de $1852^{47}$. Sin embargo, una Real Orden de 1854 primó a los matrimonios, pues estableció que a éstos no se les exigiría certificado de buena conducta, al contrario que a las madres o a los padres solteros ${ }^{48}$.

Las características de las personas que recuperaban expósitos coinciden en todas las inclusas españolas y extranjeras ${ }^{49}$. Nada de personajes importantes y acaudalados que recogían a su hijo y le cambiaban la vida. La mayoría de las madres y padres eran trabajadores, es decir, pobres, tal como confirmaban sus cédulas personales. Las mujeres que recuperaban en solitario a sus vástagos eran, en una gran parte, campesinas o sirvientas, y la gran mayoría eran analfabetas. El motivo que alegaban para haber abandonado a su hijo era, principalmente, la miseria, y le seguía el deshonor. Por eso, cuando recuperaban a sus niños, lo hacían cuando estaban ya destetados y no eran un obstáculo para que ellas pudieran seguir trabajando o pudieran emplearse como amas de lactancia. De esta manera, las madres convirtieron las inclusas, pensadas para ser centros benéficos, en centros de asistencia social.

El porcentaje de denegaciones de entrega de expósitos a los progenitores que los habían legitimado o naturalizado variaba según las inclusas. Los dos extremos serían la de Pontevedra, en donde no encontré caso alguno en el período 1872-1903, y

\footnotetext{
45 Reglamento de la Casa Provincial de Maternidad y Expósitos de Barcelona, Barcelona, 1890, art. 90-94. Reglamento para el régimen interior del Hospicio Provincial de Zaragoza, Zaragoza, 1883, art. 188 y 189. Reglamento para el régimen y gobierno del Gran Hospital de Santiago y de la Casa de Expósitos anexa al mismo, A Coruña, 1881, art. 273. MORALES ÁLVAREZ, Ángel. Casa Cuna de Ponferrada, 1775-1937, Instituto de Estudios Bercianos, Ponferrada, 2001, pp. 123-5.

${ }^{46}$ Reglamento de fecha 14-5-1852 para la ejecución de la Ley de Beneficencia de 20-6-1849, art. 24 y 26. Además, Real Orden de 15-4-1854 y Reglamentos de la Inclusa, Colegio de la Paz, Casa de Maternidad y Asilo para los hijos de las cigarreras, Madrid, 1888, art. 64.

${ }^{47}$ Reglamento de fecha 14-5-1852 para la ejecución de la Ley de Beneficencia de 20-6-1849, art. 26.

${ }^{48}$ Real Orden del 15-3-1854. AHDB, leg. j-3.023.

${ }^{49}$ FONTANA LÁZARO, Josep. "Bastardos y ladrones", en Revista de Occidente, Madrid, no 45, febrero de 1985, pag. 96. ONGER, Sergio. "Andrea Buffini e il dibattitto su "ruota" e infancia abbandonata nella Lombardia dell'Ottocento", en AA.VV. Enfance abandonnée et société en Europe, XIVXX siécle, École Française de Roma, Roma, 1991, pp. 832 y 833.
} 
la de Barcelona, en la que a finales del siglo XIX comenzaron las denegaciones y ya a principios del siglo XX fueron frecuentes.

Las naturalizaciones y las legitimaciones comportaban que los niños confiados a sus nodrizas o los que estaban prohijados fueran reclamados por las inclusas y fueran entregados a sus padres. Por regla general, no había ningún tipo de litigio al respecto porque los propios centros benéficos dejaban muy claro, por escrito, que en cualquier momento podían reclamar los expósitos confiados a sus amas. Respecto a los prohijantes, en las escrituras notariales que firmaban reconocían el derecho preferente de los padres en caso de reclamación, aunque entre el abandono y la recuperación hubiera pasado mucho tiempo.

El estudio de las personas que recogieron a sus hijos en las inclusas nos permite llegar a conocer sus características. Veremos que detrás de ellos estaba la pobreza y el analfabetismo, en contra de lo que sostenían los tratadistas y la prensa de la época, que era que los matrimonios dejaban a sus vástagos en estas instituciones por su falta de valores cristianos. Si la que abandonaba a su hijo era una mujer, las causas eran su inmoralidad y sus vicios. Concepción Arenal, en un artículo en $\mathrm{El}$ Diario de Pontevedra, en 1902, lo expresaba muy claramente,

"Dios que ha hecho al hombre tan débil al nacer, ha puesto al lado de un ser que no puede nada, otro que está dispuesto a hacerlo todo por él; enfrente de una criatura que necesita sacrificios continuos, otra cuya abnegación no tiene límite.

Cuando se rompe esa celestial armonía, cuando una mujer deja al hijo de sus entrañas en la Inclusa o en la vía pública, cuando le priva del calor de su seno, del aliento de su pecho, de la luz de sus ojos y del cariño de su corazón, entonces, hay un criminal y un desdichado; una mujer monstruo y un pobre niño que gime sin que nadie le compadezca...que muere sin que nadie le llore" 50 .

De los años revisados, 1872, 1873, 1878, 1883, 1888, 1893, 1898 y 1903, sólo hemos encontrado un caso en el que unos padres como tales reclamaron a su hija. El Presidente de la Inclusa de Pontevedra, mediante acta notarial, le hizo entrega de la misma. La niña había sido depositada a las cinco de la madrugada de un día de 1903 en el torno, llevando una nota en la que constaba que sería recogida. Además, portaba una medalla. Esta expósita estuvo con una nodriza durante siete años, después de los cuales los padres la reclamaron y la Inclusa se la devolvió, aunque se reservaba el derecho a reclamarla si no era bien tratada ${ }^{51}$. Esta niña no fue entrega-

${ }^{50}$ En las citas hemos conservador la ortografía original. ARENAL, Concepción. "Los niños pobres", en El Diario de Pontevedra, Pontevedra, n 5.610, 27-10-1902.

${ }^{51}$ Acta pública de la Diputación Provincial, 19-11-1910. AHDP, F.E. nº 15, leg. 940. 
da como hija, sino como expósita y asilada a cargo de la Inclusa, por lo que esta Institución en momento alguno cesó en su tutela, al contrario de lo que ocurría en las legitimaciones. No sabemos si hubo problemas entre la expósita y sus padres, o bien la nodriza efectuó alguna reclamación, pero si tenemos constancia de que la menor, por orden del Gobernador de la Provincia, fue devuelta seis meses después a su $\mathrm{ama}^{52}$.

Una serie de madres, nunca los padres, recogieron a sus hijos declarándose como tales. La ausencia de los varones en estos casos se correspondía con la mentalidad social de la época, que consideraba que el abandono de un hijo era responsabilidad exclusiva de la madre. La recuperación de un expósito se veía de la misma manera, y por eso la Real Orden de 15-3-1854 que regulaba las naturalizaciones cita en todo momento a las madres y en momento alguno a los padres. La figura masculina desaparecía, incluso por ley, pues estaba prohibido que cuando sólo uno de los progenitores realizara la naturalización hiciera constar el nombre del otro ${ }^{53}$.

Los expósitos reconocidos por sus madres tenían la categoría de hijos naturales, es decir, nacidos fuera del matrimonio, de padres que en el tiempo de su concepción hubieran podido casarse ${ }^{54}$. Un hijo natural era el que tenía madre o padres conocidos, por lo que para los expósitos su naturalización conllevaba el cambio de apellido, es decir, perdía el que le había impuesto el Registro Civil y adoptaba el del progenitor o progenitores que hubieran realizado la naturalización ${ }^{55}$.

Los procedimientos de recuperación de asilados de la Inclusa de Pontevedra por parte de sus madres fueron variados, pero incluían el reconocimiento público. En un caso una mujer soltera que recogió a su hijo después de cuatro meses de haberlo abandonado, lo reclamó ante el juzgado. La Inclusa se lo entregó mediante acta notarial en la que la progenitora indicaba la fecha del depósito de su hijo y el ajuar que llevaba en aquel momento. En otro caso, fue la misma Institución la que indicó a la interesada la necesidad de un certificado del Registro Civil para entregarle a su hija. Por último, una madre viuda recogió a su hijo natural mediante una escritura pública firmada por ella misma, el interventor de la Inclusa, la Directora y dos testigos. La progenitora, en este documento, describía las ropas del niño en el momento de haber sido depositado en el torno y alguna característica personal, como que tenía un poco extraviada la vista.

52 AHDP, F.E. $n^{\text {o }} 15$, libro ${ }^{\circ}$ 15.180.

${ }^{53}$ Código Civil de 1889, art. 132.

${ }^{54}$ Código Civil de 1889, art. 119. CÁMARA ÁLVAREZ, Manuel de la. Reflexiones sobre la filiación ilegítima en el Derecho Español, Tecnos, Madrid, 1975, pp. 11 y 12.

${ }^{55}$ Código Civil de 1889, art. 129-136. 
De los ocho años examinados, ya citados anteriormente, sólo hemos encontrado siete casos de niños reconocidos y recogidos por sus madres. Todos estos expósitos habían entrado en la Inclusa de Pontevedra en 1872 y 1873 y eran una pequeña parte del total de los ingresados de esos dos años, que fueron 72, y una proporción mayor de los supervivientes de ese mismo bienio, que fueron 30. Si hablamos de porcentajes, representaron el 9,7 y el 23,3, de los ingresados y los supervivientes, respectivamente.

Del estado civil de las mujeres que recuperaron a sus hijos sólo tenemos datos de tres: una era soltera y dos viudas. De los siete niños naturalizados cinco habían sido abandonados en el torno y uno en el umbral de la puerta una casa. El último, que era hijo legítimo, había ingresado en la Inclusa mediante una solicitud de su madre.

CUADRO N ${ }^{\circ}$ 5: Estado civil y vecindad de las madres que recogieron a sus hijos en la Inclusa de Pontevedra, 1872-187356.

\begin{tabular}{ccccccccc} 
& & & & \multicolumn{4}{c}{ Vecindad } \\
\cline { 5 - 9 } & \multicolumn{3}{c}{ Estado civil } & & \multicolumn{4}{c}{ Pontevedra } \\
\hline Soltera & Casada & Viuda & Sin datos & Total & Capital & Cercanías & Resto de la provincia & S/d \\
\hline & & 2 & 4 & 7 & 2 & 1 & 2 & 2 \\
\hline
\end{tabular}

Ninguno de estos siete niños entró de recién nacido. La mayoría contaba con algunos meses de vida e, incluso, con algunos años. Fueron recogidos tras días o meses de estancia en la Inclusa ${ }^{57}$, pero a una edad en la que, menos en un caso, la lactancia no era tan imprescindible y podía sustituirse o completarse con otro tipo de alimentación ${ }^{58}$. Creemos que esto evidencia situaciones difíciles por parte de las madres y también una estrategia de supervivencia. Se abandonaba el hijo o se solicitaba formalmente su ingreso en la Inclusa cuando las circunstancias eran muy adversas y se recogía cuando ya no era necesario pagar a una nodriza y era más fácil, además, dejarlo a cargo de otra persona, o bien cuando cesaban las presiones familiares sobre las madres solteras. Una progenitora que en 1890 solicitaba la entrega de su hija "como tal madre", explicaba su situación en el momento en el que la había echado al torno, "...enferma, sin tener recursos ni para cuidarse ella, ni tampoco por consiguiente para poder pagar un ama" ${ }^{59}$. Además, era soltera, sir-

${ }^{56}$ AHDP, F.E. n ${ }^{\circ}$ 15, leg. 940, 960, 964, 980, 982, y 993. Además, libros $n^{\text {o }} 15.169$ al 15.172, $15.174,15.176$ al 15.178, y 15.180 .

57 Idem.

58 Idem.

${ }^{59}$ Instancia a la Comisión de Diputados de la Inclusa, 13-3-1890. AHDP, F.E. nº 15, leg. 940. 
vienta y también lavandera, y analfabeta. Otra madre, en 1872, abandonó a su hijo en el torno cuando tenía cinco meses y, al mismo tiempo, empezó a trabajar de nodriza interna en la Inclusa. Esta mujer era soltera y recuperó a su retoño cuatro meses después. Por último, otra mujer que había expuesto en el torno a su hijo de tres años alegaba, en la instancia en la que solicitaba su recuperación, que era viuda, pobre de solemnidad, no había podido lactar a su niño porque no tenía leche, y que había sido presionada,

“...había sido inducida a ello (al abandono) por otras personas, mas no pudiendo vivir tranquila, sin que esté en su compañía dicho su hijo, ruega se le entregue" 60 .

El último motivo que había enunciado esta madre para explicar el abandono de su hijo se repite en otras instancias, unido al de la falta de consentimiento, "le arrebataron (a su hijo) de su poder sin su consentimiento"61. No obstante, hemos de tener en cuenta que la mayoría de las mujeres eran analfabetas y que estas instancias eran redactadas por escribanos que quizás repetían fórmulas que se utilizaban en otras inclusas. A pesar de ello, las ropas con las que eran abandonados estos niños ya delataban su extracción social pues, al igual que las del resto de los expó$\operatorname{sitos}^{62}$, eran escasas y estaban viejas y remendadas. Uno de los menores llevaba un pedazo de tela que le servía de pañal, otro fue abandonado dentro de un cesto viejo, envuelto en un pedazo de tela y semidesnudo. De otro, transcribimos la anotación de su ajuar en el libro de registro de entrada de la inclusa,

“Camisa de algodón vieja y con remiendos, un pañuelo viejo y roto, una toalla de hilo rota y sucia que le servía de pañal y un gorra vieja"63.

La recuperación de un hijo significaba el pago de las cantidades que la Inclusa hubiera gastado ${ }^{64}$. La Diputación Provincial actuó de una manera irregular y cambiante. En 1873 entregó a una madre su hijo natural sin cobrarle cantidad alguna por los 17 días que había pasado en la Inclusa tras haber sido echado al torno ${ }^{65}$. Sin embargo, en 1879, a una mujer que reclamó a su hijo después de cuatro meses de haberlo abandonado en el torno, la Diputación le exigió el pago de 619 pesetas, a

\footnotetext{
${ }^{60}$ Instancia de 1876 de la madre del expósito 63/73. AHDP. F.E. $\mathrm{n}^{\circ} 15$, leg. 980.

${ }^{61}$ Instancia de la madre de la expósita 337/78. AHDP. F.E. no ${ }^{\circ} 15$, leg. 940.

${ }^{62}$ RODRÍGUEZ MARTÍN, Ana María. "Algúns aspectos relativos á Inclusa de Pontevedra, 18721903”, en Pontevedra. Revista de Estudios Provinciais, Pontevedra, n 16, 2001, pag. 76.

${ }^{63}$ Ropas del expósito 63/73. AHDP, F.E. $n^{\circ} 15$, libro $n^{\circ} 15.169$.

${ }^{64}$ Reglamento del 14-5-1852 para la ejecución de la Ley de Beneficencia del 20-6-1849, art. 24.

${ }^{65}$ AHDP, F.E. ${ }^{\circ} 15$, leg. 980.
} 
pesar de que esta madre era soltera, no tenía un trabajo remunerado y era menor de edad $^{66}$. Por el contrario, en 1883, otra mujer presentó un certificado conforme no era contribuyente y eso significó que la Inclusa no le cobrara nada por la manutención de la hija que estuvo a cargo de la Institución durante cuatro años ${ }^{67}$. Esta última postura coincide con la de otras inclusas españolas que aceptaban el certificado de pobreza del alcalde del barrio o del pueblo donde residiera la madre como eximente del pago del importe la lactancia y del cuidado del niño recogido ${ }^{68}$.

Había una serie de expósitos que creemos que fueron también recogidos por sus madres, aún cuando éstas no constasen como tales oficialmente. Estas mujeres eran denominadas nodrizas sin retribución y recogían asilados de la Inclusa de Pontevedra presentando solamente el certificado de buena conducta de su párroco y, si el niño a recoger era lactante, un certificado médico conforme tenían leche para amamantar ${ }^{69}$. Estas amas no constaban en los libros de registro de nodrizas, aunque sí en los de expósitos con la fórmula "entregado el expósito a..., nodriza sin retribución”. El número de niños entregados de esta manera fue de 70 sobre los 600 ingresados en los siete años que consideramos desde 1873 a $1903^{70}$. De algunas de estas mujeres sin duda podemos afirmar que eran sus madres porque ellas así lo hicieron constar en sus instancias ${ }^{71}$, o bien porque, pasado un tiempo desde la recuperación del hijo, lo reconocían de forma oficial al naturalizar al expósito a su cargo mediante testamento ${ }^{72}$. De otras, podemos decir que probablemente fueran las madres porque en sus instancias de solicitud de entrega de un expósito en concreto copiaron el contenido de la nota con la que el niño fue abandonado e, incluso, presentaron una copia $^{73}$. Otras veces, el asilado reclamado llevaba el mismo apellido que la mujer que se presentaba como nodriza sin retribución. Esto no era casualidad, sino que en la nota que había portado el recién nacido al ingresar en la Inclusa se pedía que le fuera impuesto precisamente ese apellido en el Registro Civil ${ }^{74}$.

\footnotetext{
${ }^{66}$ AHDP, F.E. $n^{\circ} 15$, leg. 940.

${ }^{67}$ Sesión de la Comisión de Diputados encargada de la Inclusa, 30-4-1879 y 7-4-1883. AHDP, F.E. $\mathrm{n}^{\mathrm{o}} 15$, libro $\mathrm{n}^{\mathrm{o}} 15.168$.

${ }^{68}$ AHDB, leg. j-2.851 al j-2.885.

${ }^{69}$ Sesión de la Comisión de Diputados encargada de la Inclusa, 28-6-1881. AHDP, F.E. n ${ }^{\circ}$, libro $\mathrm{n}^{\mathrm{o}} 15.168$.

${ }^{70}$ Hemos estudiado los años 1872, 1873, 1878, 1883, 1888, 1893, 1898 y 1903. AHDP, F.E. $\mathrm{n}^{\circ} 15$, libros $n^{\circ} 15.169$ al 15.172, 15.174, 15.176 al 15.178, y 15.180. Además, leg. 940, 960, 964, 980, 982 y 993.

${ }^{71}$ Instancia de la madre de la niña 337/79 a la Comisión de Diputados encargada de la Inclusa, 113-1879. AHDP, F.E. no 15, leg. 940.

${ }^{72}$ AHDP, F.E. $n^{\circ} 15$, libro $n^{\circ} 15.174,15.176,15.179$ y leg. 940.

${ }^{73}$ AHDP, F.E. $n^{\circ} 15$, libros $n^{\circ} 15.177,15.178$ y 15.180.

${ }^{74}$ AHDP, F.E. $n^{\circ} 15$, libro $n^{\circ} 15.176$.
} 
Creemos que la actuación de estas mujeres era una estrategia de supervivencia, pues la mayoría, que eran solteras ${ }^{75}$, recogían a estos expósitos después de los trece meses $^{76}$, precisamente cuando ya no era necesaria su lactancia. El tiempo pasado por los niños en la Inclusa habría permitido a estas madres ejercer un trabajo o bien emplearse como nodrizas particulares.

\subsection{Los prohijamientos}

Los prohijamientos de los expósitos estaban contemplados en el Reglamento de 1852 que desarrollaba la Ley de Beneficencia de 184977. Las únicas condiciones que se exigían a los prohijantes eran la honradez y los medios suficientes para mantener a un menor, aunque la investigación de las condiciones económicas y morales de los prohijantes, y la exigencia a éstos del cumplimiento de una serie de deberes no se llevaban a cabo en todos los establecimientos de beneficencia ${ }^{78}$. Los acogidos prohijados continuaban hasta su mayoría de edad bajo la tutela de las inclusas a las que pertenecían.

En las inclusas españolas las personas que prohijaban un asilado tenían que firmar una escritura pública ${ }^{79}$. En la Inclusa de Pontevedra, en la escritura notarial constaba como el Presidente de la Inclusa, que era el de la Diputación Provincial, entregaba un expósito que tenía bajo su tutela. A su vez, los prohijantes se comprometían a sostener y educar al acogido de manera conveniente, "con arreglo a su posición y en la Religión Católica". Hemos encontrado también la entrega de una asilada mediante documento firmado por el abogado del Estado. Igualmente en este caso se especificaba que los prohijantes educarían a la expósita en cuestión en la más sana moral, "como si fuera hija propia" ${ }^{80}$. Lo básico en ambos tipos de documentos es la certificación de la entrega de un menor a cargo de la Inclusa de Pontevedra y la especificación de las obligaciones de la persona o personas que lo reciben, además de la advertencia de que el niño en cuestión tendría que ser devuelto a la Institución si un familiar suyo o persona de mejor derecho lo reclamara. Sin embargo, la Inclusa no perdía la tutela sobre estos acogidos y encargaba de su vigi-

\footnotetext{
${ }^{75}$ AHDP, F.E. $\mathrm{n}^{\circ} 15$, libros $\mathrm{n}^{\circ} 15.169$ al $15.172,15.174,15.176$ al 15.178 y 15.180.

${ }^{76}$ AHDP, F.E. $\mathrm{n}^{\mathrm{o}} 15$, libros $\mathrm{n}^{\circ} 15.169$ al 15.172, 15.174, 15.176 al 15.178, y 15.180. Además, leg. 940, 960, 964, 980, 982 у 983.

${ }^{77}$ Reglamento de 14-5-1852 para la ejecución de la Ley de Beneficencia del 20-6-1849, art. 22 y 23.

${ }^{78}$ DÍEZ RODRÍGUEZ, Fernando. La sociedad desasistida. El sistema benéfico asistencial en la Valencia del siglo XIX, Diputación de Valencia, Valencia, 1993, pp.138-141.

${ }^{79}$, leg. j-2.851 al 2.885. GALICIA PINTO, Isabel. La Real Casa Hospicio de Zamora. Asistencia social a marginados, 1798-1850, Diputación Provincial de Zamora, Zamora, 1985, pag. 113.

${ }^{80}$ AHDP, F.E. $n^{\circ} 15$, leg. 940.
} 
lancia a los curas párrocos. Es más, podía legalmente reclamar a cualquier prohijado si así lo creyera conveniente y en vistas de los informes privados que solicitara cuando estimara conveniente, y según el buen o mal trato que se dispensara al menor $^{81}$.

En la escritura notarial también constaba el importe de la dote que se entregaba a los niños prohijados. Dado el carácter rural de la población gallega, esas donaciones eran, en la inmensa mayoría de los casos, bienes agrícolas, no monetarios. Solían consistir en la vivienda y en tierras, y su valoración iba desde las 200 pesetas a las 350. No obstante, la Inclusa, en su política de favorecer los prohijamientos, aceptaba otras fórmulas. Una de ellas era admitir que los prohijados fueran nombrados herederos de los bienes de sus prohijantes, pero sin especificar patrimonio inmobiliario o monetario alguno, seguramente porque era poco menos que inexistente. Otra fórmula era la aprobación de la promesa de la entrega de una determinada cantidad de dinero, normalmente cien pesetas, a la prohijada cuando tomara estado, es decir, cuando se casara o ingresara como monja. La Institución llegó, incluso, a aceptar la palabra de unos prohijantes de que la niña que acogían sería declarada heredera cuando hicieran testamento. En todos los casos, si la Inclusa reclamara a los prohijados, éstos se quedarían sin los bienes prometidos o donados.

La Inclusa no ponía inconvenientes a los prohijamientos y, desde luego, no hacía averiguaciones reservadas sobre la conducta de los solicitantes, como ocurría en otros establecimientos benéficos similares ${ }^{82}$. Por ello, no hemos encontrado denegaciones de prohijamiento. No obstante, algunas personas consideraron erróneamente que una nota de recomendación podía facilitarles los trámites, y tenemos constancia de dos. Una, de 1910, era del alcalde de Vigo y presidente de la Diputación Provincial, y la presentaba una mujer soltera de dicha ciudad que quería prohijar a una niña dejada en el torno en 1903. La otra, data de 1911 y la autora fue la abadesa del Monasterio del Divino Salvador de Ferreira de Pantón. En ella garantizaba la honradez de unos consortes que deseaban prohijar a una expósita de nueve años que ya tenían en su compañía, pues la esposa había sido su nodriza ${ }^{83}$.

Los prohijamientos eran distintos a las adopciones. En estas últimas los menores tenían el derecho a llevar el apellido de sus padres adoptivos y a here-

${ }^{81}$ Sesión de la Comisión de Diputados encargada de la Inclusa, 4-5-1882. AHDP, F.E. n 15 , libro $\mathrm{n}^{\circ} 15.168$.

${ }^{82}$ AHDB, leg. j-2.432 y j-2.434.

${ }^{83}$ AHDP, F.E. n ${ }^{\circ} 15$, libro ${ }^{\circ} 15.179$. 
dar sus bienes, cosa que no ocurría con los prohijados, que conservaban el apellido que le había puesto el juzgado en el que habían sido registrados y, además, no tenían derecho a herencia alguna. Incluso el carácter de los prohijamientos y las adopciones era diferente. Los primeros lo tenían administrativo y las segundas, civil ${ }^{84}$.

En la Inclusa de Pontevedra los niños que se daban en prohijamiento eran los hijos de padres desconocidos. Estos asilados eran los que, en principio, tenían menos probabilidades de ser reclamados por sus progenitores. Por tanto, no se concedía el prohijamiento de acogidos que fueran hijos legítimos, y tampoco el de hijos naturales, aunque hemos encontrado una excepción. Se trataba de dos hermanos que fueron prohijados por personas diferentes, y que habían ingresado con un oficio del alcalde de la localidad en la que vivía su madre, soltera, enferma y pobre. Nosotros no hemos podido establecer si la Inclusa comprobó el fallecimiento de la madre.

Hemos calculado el porcentaje anual de prohijamientos teniendo en cuenta no el total de ingresados, sino el de los supervivientes, pues ya vimos que la mayoría de los asilados morían en su primer año de vida y los prohijamientos se hacían cuando los acogidos tenían ya varios años. Teniendo en cuenta esto, si observamos el cuadro $\mathrm{n}^{\circ} 6$ nos daremos cuenta de que los prohijamientos no fueron abundantes y su número varió mucho según los años, tal como ocurrió en otras inclusas españolas ${ }^{85}$. Para facilitarlos, la de Lugo corría con los gastos de las escrituras de prohijamiento ${ }^{86}$. En otras inclusas, como las de Santiago, Málaga, y también la de Pontevedra, se permitía que prohijaran expósitos no solamente matrimonios, sino también personas solteras ${ }^{87}$, al contrario de lo que ocurría en otros centros benéficos ${ }^{88}$. Por esa razón, si observamos el cuadro que sigue, podemos ver que en la Inclusa de Pontevedra hubo más prohijantes solteros que casados.

${ }^{84}$ SEVILLA BUJALANCE, Juan Luis. Los niños expósitos y desamparados en nuestro Derecho histórico, Universidad de Córdoba, Córdoba, 2001, pp. 110-117.

${ }^{85}$ AHDB, leg. j-3.061 al 3.112.

${ }^{86}$ Reglamento de la Casa de Maternidad y Espósitos de la Provincia de Lugo, Lugo, 1863, art. 118 y 120.

${ }^{87}$ Reglamento para el régimen y gobierno del Gran Hospital de Santiago y de la Casa de Expósitos anexa al mismo, A Coruña, 1881, art. 227. Reglamento para el régimen interior administrativo y económico del establecimiento provincial de Espósitos de Málaga y sus hijuelas, Málaga, 1858, art. 62.

${ }^{88}$ AHDB, leg. j-2.851 al j-2.885, j-3.227, 714 y 772. 
CUADRO N ${ }^{\circ}$ 6: Asilados de la Inclusa de Pontevedra prohijados y estado civil de los prohijantes, $1872-1903^{89}$

\begin{tabular}{lcccccc} 
& & & & \% sobre los & \multicolumn{2}{c}{ Prohijantes } \\
Años & Niñas & Niños & Total & Supervivientes & Solteros & Matrimonios \\
\hline 1873 & 1 & - & 1 & 0,2 & 1 & - \\
1878 & - & 1 & 1 & 0,3 & 1 & - \\
1883 & 3 & - & 3 & 12 & 1 & 2 \\
1888 & 4 & 1 & 5 & 10,7 & 3 & 2 \\
1893 & 3 & - & 3 & 8,1 & 1 & 2 \\
1898 & - & - & - & - & - & - \\
1903 & 4 & - & 4 & 6,3 & 2 & 2 \\
\hline Total & 15 & 2 & 17 & 6,4 & 9 & 8 \\
\hline$\%$ & 88,2 & 11,8 & & & &
\end{tabular}

Las edades de los expósitos prohijados variaban entre los seis y los nueve años. A esta edad los niños ya no necesitaban tantos cuidados e, incluso, podían ya realizar algún servicio a sus prohijantes. Todos los prohijados, menos dos, fueron niñas. Creemos que se debía a que los prohijantes esperaban de ellas que tuvieran una serie de cualidades que se consideraban propias del sexo femenino ${ }^{90}$ : la docilidad, el fuerte sentido de la familia, la realización de las faenas caseras, la abnegación y el cuidado de los ancianos y enfermos.

Respecto a los prohijantes, ya habíamos visto que estaban casi igualados el número de casados y de solteros. Estos últimos eran mayoritariamente mujeres. Concretamente, de los nueve solteros que constan en el cuadro anterior, ocho son del sexo femenino.

La profesión mayoritaria de los prohijantes varones era la de labrador, aunque hemos encontrado dos marineros y un cantero. La de las mujeres era también la de agricultora, aunque constaban cuatro esposas que se dedicaban a sus labores y una soltera que figuraba como propietaria ${ }^{91}$. Respecto a la edad de los prohijantes, no contamos con datos completos. De dos mujeres solteras sabemos que tenían cuarenta años, y una tercera, con el mismo estado civil, cincuenta. Las casadas eran también mayores, una contaba más de 30 años y otra más de cuarenta. De los hom-

${ }^{89}$ AHDP, F.E. $n^{\circ} 15$, leg. 940. Además, libros no 15.169 al 15.172, 15.174, 15.176 al 15.178, y 15.180 .

${ }^{90}$ HERNÁNDEZ IGLESIAS, Fermín. Tratado práctico de la Beneficencia particular, Madrid, 1874, pag. 208. ARENAL, Concepción. La filantropía...Op. cit., pag. 113.

${ }^{91}$ AHDP. F.E. $n^{\circ} 15$, leg. 940. 
bres sólo disponemos de información sobre tres casados. Dos de ellos sobrepasaban los cincuenta años, y el tercero tenía cuarenta ${ }^{92}$. Vemos, pues, que todos ellos eran bastante mayores.

El nivel cultural de los prohijantes era muy bajo. Si tenemos en cuenta a las mujeres, tanto solteras como casadas, de dieciséis, la mitad eran analfabetas. Si nos fijamos en el total de hombres, de nueve no sabían ni leer ni escribir ocho, es decir, el 88,8 por ciento ${ }^{93}$.

A través de las instancias solicitando prohijar un expósito y de las escrituras notariales que firmaban los interesados, podemos ver algunas de las razones que les llevaban a acoger a un expósito. Tres de los matrimonios afirmaban no haber tenido descendencia. Otros dos no lo hacían constar, pero la edad de las esposas hacía imposible un embarazo. Otras dos mujeres solteras se hallaban en la misma situación. Es decir, el motivo de estos prohijamientos era el no haber tenido hijos propios, pero si nos fijamos en la edad tan avanzada de los prohijantes podía ser también el de la búsqueda de alguien que les cuidara en su vejez.

La mayoría de los prohijantes, tal como podemos ver en el cuadro que sigue, vivían en un entorno rural. De Pontevedra capital no prohijó un expósito ni una sola persona.

CUADRO N ${ }^{\circ}$ 7: Vecindad de los prohijantes de asilados de la Inclusa de Pontevedra, 1872$1903^{94}$.

Pontevedra

$\begin{array}{lllll}\text { Capital Municipio } & \text { Vigo capital } & \text { Resto de la provincia Sin datos } & \text { Total }\end{array}$

\begin{tabular}{lcccccc} 
Número & - & 3 & 3 & 10 & 1 & 17 \\
$\%$ & - & 17,6 & 17,6 & 58,9 & 5,9 & 100 \\
\hline
\end{tabular}

De la Inclusa de Pontevedra no contamos con documentación que nos permita establecer la labor de tutela que pudo llevar a cabo la Institución sobre los prohijados. Si tenemos en cuenta cómo fue la que ejerció sobre el resto de los niños a su cargo $^{95}$, tenemos que deducir que fue deficiente, como ocurría en el resto de inclu-

\footnotetext{
92 Idem.

${ }^{93}$ Idem.

${ }^{94}$ AHDP, F.E. $n^{\circ} 15$, libros no 15.169 al 15.172, 15.174, 15.176 al 15.178, y 15.180. Además, leg. 940, 960, 964, 980, 982 y 983.

${ }^{95}$ RODRÍGUEZ MARTÍN, Ana María. “La Inclusa de Pontevedra...”, Op. cit., pp. 184-185.
} 
sas españolas ${ }^{96}$. En todas ellas, no obstante, hubo una mejora que se inicia en la última década del siglo XIX. En la Inclusa de Pontevedra tenemos en 1900 constancia de la supervisión sobre los prohijados porque hemos encontrado la actuación enérgica de la Institución ante la situación de una niña que había sido prohijada por un matrimonio. Esta pareja tenía una convivencia difícil y se había separado. La Inclusa temía que la expósita, que vivía en Madrid con la esposa, no se hallara bien atendida, por lo que decidió reclamarla a través del Gobernador de Pontevedra y del de Madrid,

\begin{abstract}
"Según voz pública las relaciones que deben existir entre los esposos no son nada satisfactorias; y como los referidos esposos hayan recogido...una niña expósita...con objeto de prohijarla, sin que hasta el día de hoy hayan hecho documento público alguno a favor de la misma, y teniendo presente que el Don B.S. (el esposo) hace mas de dos años que se halla en esta capital, después de estar algún tiempo ausente, habiendo dejado en la Villa y Corte de Madrid a su Esposa y a la niña expósita sin saber de que manera y condiciones, propone (la Comisión de Diputados encargada de la Inclusa) que antes que la mencionada niña Expósita quede en completo abandono, si es que ya no lo está hoy, y que por consiguiente llegue dentro de poco tiempo a ser una joven desgraciada (sea recogida)" 97 .
\end{abstract}

Los prohijamientos podían añadir más inestabilidad vital a los expósitos si se rompían, bien fuera por fallecimiento de los prohijantes o porque éstos quisieran devolver al asilado a su cargo. Estos niños, que ya habían pasado por la Inclusa y por una o más nodrizas, y luego por unos prohijantes, se veían empujados otra vez a un cambio más, bien fuera con otra familia o bien con otra institución, en este caso el Hospicio Provincial. Uno de estos casos fue el de una menor ingresada en la Inclusa en 1901, y que fue prohijada a los once años. Tras el fallecimiento de sus prohijantes, los sobrinos de éstos no quisieron hacerse cargo de ella, por lo que fue recogida por la Inclusa y entregada en el mismo año a otra familia con la que se quedó definitivamente ${ }^{98}$. Otros caso fue el de una niña de la generación de 1902 que, tras vivir en la Inclusa, luego con una nodriza y después con una prohijante, acabó a los 14 años en el Hospicio ${ }^{99}$.

96 AHDB, leg. j-2.400, j-2.429, j-2.431, j-3.017, j-3.020 y j-3.029. "Miscelánea", en Revista de Beneficencia, Madrid, no 12, 8-11-1887, pag. 6. VALVERDE LAMSFUS, Lola. Op. cit., pp. 167-168 y 173-178. URIBE ETXEBARRÍA, Arántzazu. Op. cit., pag. 150.

${ }^{97}$ Sesión de la Comisión de Diputados encargada de la Inclusa, 24-4-1900. AHDP, F.E. nº 15, libro $\mathrm{n}^{\circ} 15.168$.

98 AHDP, F.E. $n^{\text {o }} 15$, libro ${ }^{\circ} 15.179$.

99 Idem. 


\subsection{El traslado al Hospicio Provincial}

La mayoría de los niños de la Inclusa de Pontevedra que, a la edad reglamentaria, eran trasladados al Hospicio Provincia eran varones, un 70,5\%, mientras que las mujeres representaban el $29,5 \%$. Este fenómeno era común a todos los establecimientos benéficos similares, y la causa es que eran prohijadas más niñas que niños y, por eso, no había equilibrio de sexos entre los asilados de siete años que permanecían en las inclusas en espera de su traslado a los hospicios.

CUADRO No 8. Niños de la Inclusa de Pontevedra trasladados al Hospicio Provincial, 1872$1903^{100}$

\begin{tabular}{lcccc} 
Año & Niños & Niñas & Total & $\begin{array}{c}\text { \% sobre los supervivientes de los } \\
\text { Ingresados anualmente en la inclusa }\end{array}$ \\
\hline 1873 & - & 4 & 4 & 19 \\
1878 & 8 & 3 & 11 & 25 \\
1883 & 6 & 1 & 7 & 20 \\
1888 & 5 & 3 & 8 & 14,3 \\
1893 & 9 & 2 & 11 & 29,7 \\
1898 & 9 & 3 & 12 & 22,6 \\
1903 & 6 & 3 & 9 & 14,1 \\
\hline & & & & 21,4 \\
\hline
\end{tabular}

El traslado de los asilados de la Inclusa de Pontevedra al Hospicio Provincial se hacía, por regla general, a los siete años, que era la edad a la que las nodrizas que no querían seguir cuidando a los niños, y que ya no cobraban de la Inclusa, los devolvían. No obstante, en bastantes ocasiones los acogidos ingresaban en el Hospicio un poco más tarde debido al retraso en la reclamación oficial del niño al ama y al tiempo que ésta tardaba en devolverlo. Otros asilados, sin embargo, eran trasladados antes de los siete años. Se trataba de los que habían entrado en la Inclusa ya mayores, a partir de los tres años. Como ya estaban destetados, sólo pasaban unos días o unos meses en este centro benéfico y luego iban al Hospicio ${ }^{101}$.

También ingresaban en el Hospicio expósitos bastante mayores. Eran los que habían sido devueltos por sus amas que, en principio, se los habían quedado a pesar de que habían cumplido los siete años y ya no cobraban por su cuidado. Hemos encontrado doce casos. En su mayoría se trataba de varones, nueve, y de tres niñas.

100 AHDP, F.E. n ${ }^{\mathrm{o}} 15$, libros n ${ }^{\mathrm{o}} 15.169$ al 15.172, 15.174, 15.176 al 15.178, y 15.180.

${ }^{101}$ AHDP, F.E. no 15, leg. 981 y libros no 15.169 al 15.172, 15.174, 15.176 al 15.178, y 15.180. 
Todos ellos habían sido devueltos entre los diez y los once años, aunque hubo dos excepciones, la de un expósito a los doce y otro a los catorce. Sólo en dos casos conocemos las causas exactas de estos retornos de niños a la Inclusa. El primero se trataba de un acogidos que ingresó a los catorce años porque su ama había fallecido, y el segundo era un menor que a los diez años fue devuelto por su nodriza que lo había recogido sin retribución. Del resto, y si nos fijamos en la coincidencia en la edad de las devoluciones, podemos pensar que la causa principal fue el comienzo de la adolescencia, tal como ocurría en otras inclusas. Cuando un ama no podía gobernar al muchacho a su cargo, o si éste se negaba a trabajar, la vuelta de expósito a la Inclusa, y luego su rápido traslado al Hospicio Provincial, se presentaba como una opción.

Al llegar la edad reglamentaria los asilados en el Hospicio lo abandonaban, aunque algunos por sus deficiencias psíquicas se quedaban en él, y allí morían a edades variadas ${ }^{102}$. Otros, antes de la edad de salida, se fugaban y, al igual que en los demás establecimientos benéficos similares ${ }^{103}$, eran buscados y reclamados. Incluso, se insertaban anuncios en el Boletín Oficial de la Provincia ${ }^{104}$ y en la prensa para su captura ${ }^{105}$.

Tenemos muy pocos datos de los acogidos cuando la Inclusa y el Hospicio de Pontevedra abandonaban su tutela. Esta misma dificultad se presenta cuando se estudian otros centros benéficos y constatamos que la única información con la que podemos contar es con la que facilitaban los mismos expósitos al solicitar su partida de nacimiento, bien para casarse o bien para pedir su jubilación ${ }^{106}$. A través de estos documentos hemos podido ver que los interesados tenían problemas de identidad. Algunos no conocían ni su edad ni su nombre exacto, y firmaban con el apellido Expósito que era el que le adjudicaban en el pueblo sus vecinos e, incluso, las autoridades locales, todo ello a pesar de tener un apellido propio, tal como establecía la Ley de Registro Civil de $1870^{107}$. Por eso, en la Inclusa de Pontevedra, en 1932, se le contestó a una expósita que había ingresado en 1875, “Tiene usted 57

${ }^{100}$ AHDP, F.E. $\mathrm{n}^{\mathrm{o}} 15$, libros $\mathrm{n}^{\mathrm{o}} 15.169$ al 15.172, 15.174, 15.176 al 15.178, y 15.180.

${ }^{101}$ AHDP, F.E. $n^{\circ} 15$, leg. 981 y libros no 15.169 al 15.172, 15.174, 15.176 al 15.178, y 15.180.

102 AHDP, F.E. $n^{\circ} 15$, libros $n^{\circ} 15.214,15.124$ y 15.125

${ }^{103}$ En la Casa de Maternidad y Expósitos de Barcelona se daba cuenta a la Policía, y se ordenaba su búsqueda y captura, aunque solía ser de expósitas y no de expósitos. A las primeras, se las buscaba y se las reintegraba a la Institución aunque tuvieran, incluso, 20 años. AHDB, leg. j-3.103, j-2.398, $\mathrm{j}-2.431, \mathrm{j}-2.433$ y j-2.434.

104 Boletín Oficial de la Provincia de Pontevedra, 19-5-1906.

105 "Miscelánea", en El Anunciador, Pontevedra, no 4.709 al 4.719, del 20-10-1892 al 30-10-1892.

106 ROMÁN PORTAS, M Ma Luz. La asistencia social en Galicia: el Hospicio de Pobres de Santiago de Compostela (1860-1900), Diputación Provincial de A Coruña, A Coruña, 1989, pp. 97-98 y 167-196. VALVERDE LAMSFUS, Lola. Op. cit., pag. 272. AHDB, leg. j-2.271 al j-2.434, y j-3.029. ${ }^{107}$ Ley de Registro Civil del 17-6-1870, art. 34. 
años y no 50 como dice, y no se llama Engracia Expósita sino J. G. P. del P. B.”108. Es decir, no coincidía ni el nombre, pues la realidad es que tenía tres, ni el apellido.

Esta falta de información sobre la propia identidad la vemos también en el caso de un expósito que había solicitado un certificado de soltería para contraer matrimonio. La Institución le contestó que le era necesario saber su fecha de nacimiento y el nombre y apellidos de la nodriza que lo había cuidado. El muchacho replicó por escrito que no le era posible facilitar esos datos,

“...de la edad que tengo y la nodriza que me crió eso me es de todo punto imposible darle datos alguno pues yo de lo único que le puedo averigüar lo primero es de la edad que tengo que son hasta la fecha 25 años cumplidos y de la nodriza que me crio de lo unico que me puedo rrecordar es de haberse llamado que no estoy seguro del todo es Florinda o Florentina..."109

Esta identidad difusa de los expósitos se corresponde con su falta de raíces: no contaban con padres, ni con apellidos propios, ni con patrimonio ni casa familiar. Esta circunstancia hacía que tuvieran poco peso social, que se veía reflejado incluso en la prensa pontevedresa ${ }^{110}$. En ella, la Inclusa y todo lo relacionado con ella no aparecía casi nunca citado. Sólo hemos encontrado dos sueltos periodísticos. En el primero, se informaba del acuerdo de la Comisión Provincial para que ingresara un niño legítimo. En el segundo, con ocasión de la epidemia de sarampión en Pontevedra, se sugería a la Diputación que enviara desinfectantes a la Inclusa ${ }^{111}$. Respecto a los expósitos, únicamente aparecían en algunas listas de fallecidos mensuales, englobados en la población general de la ciudad ${ }^{112}$. Sólo los trasladados al Hospicio tenían más cabida en la prensa, pues con cierta frecuencia salían noticias breves relativas a actuaciones de la banda de música o a comidas extraordinarias con motivo de la Nochebuena $^{113}$. También en otras ocasiones se citaba esta última institución como beneficiaria de los fondos obtenidos por conciertos o veladas benéficas ${ }^{114}$.

108 Oficio de la Inclusa de Pontevedra, 1-1-1932. AHDP. F.E. nº 15, leg. 940.

${ }^{109}$ Escrito de un expósito de la generación de 1902 a la Inclusa de Pontevedra, 28-7-1927. AHDP, F.E. $\mathrm{n}^{\mathrm{o}} 15$, leg. 940.

${ }^{110}$ Los periódicos y los años que hemos revisado son: Crónica de Pontevedra, 1886 y 1887. El Anunciador, 1881 y 1892. El Diario, 1885-1887. El Diario de Pontevedra, 1879 y 1902. El Libre Pontevedrés, del 13-8-1854 al 1-12-1854.

111 "El sarampión en Pontevedra", en Crónica de Pontevedra, Pontevedra, n 158, 9-11-1886.

112 Suelto en Crónica de Pontevedra, Pontevedra, $\mathrm{n}^{\circ} 365,4-6-1887$.

113 "Miscelánea", en El Anunciador, Pontevedra, no 4.587, 11-4-1892. "La Banda del Hospicio", en El Diario de Pontevedra, Pontevedra, $\mathrm{n}^{\circ}$ 5.300, 28-1-1902. "Apuntes noticieros", en El Diario de Pontevedra, Pontevedra, ${ }^{\circ}$ 5.603, 18-12-1902.

114 "Miscelánea", en El Anunciador, Pontevedra, n 1.385, 20-9-1881. 
Esta invisibilidad de la Inclusa y los expósitos la hallamos también en los libros actuales sobre la historia de la ciudad de Pontevedra, pues no hemos encontrado mención alguna del centro benéfico que estudiamos ${ }^{115}$.

\section{CONCLUSIONES}

Al contrario de lo que ocurrió en muchas inclusas españolas, el número de niños ingresados en la Inclusa de Pontevedra no descendió a lo largo del período que analizamos, lo mismo que el porcentaje de entrados por el torno. El destino de una gran parte de los acogidos en la Institución era la muerte que, en muchas ocasiones, afectaba a más de la mitad de los ingresados anualmente y que se producía, sobre todo, en su primer año de vida. No obstante, la mortalidad en la Inclusa se situaba en el término medio de la que presentaban otros centros benéficos similares en España. Las causas de los fallecimientos en la Institución pontevedresa radicaban en su falta de medios y en el estado de debilidad y enfermedad en el que ingresaban los niños, consecuencia de la pobreza de las madres. En el primer caso, la escasez de fondos provocaba que se pagaran a las nodrizas sueldos muy bajos, por lo que pocas mujeres se presentaban para hacer este trabajo. Por esta razón, los acogidos tenían que esperar para tener un ama externa de lactancia demasiado tiempo, residiendo en unos locales que no reunían las condiciones adecuadas para albergar menores y, sobre todo, recién nacidos. Cuando, por fin, eran entregados a las nodrizas externas, los asilados tenían que hacer un largo viaje, pues solamente a las mujeres de zonas deprimidas y alejadas de la Capital les resultaba atractivo el bajo salario de la Inclusa.

Algunos niños supervivientes eran recogidos, pasado un tiempo, por sus familiares. Solamente en un caso fueron sus padres quienes reclamaron a un expósito. En el resto, se trataba de mujeres solas que, como madres, reconocían a sus hijos y se los llevaban consigo, pero cuando los menores no necesitaban necesariamente mamar, lo que les permitía a ellas ejercer un trabajo o continuar empleadas como amas de lactancia. Esta forma de actuar, verdadera estrategia de supervivencia, estaba provocada por su pobreza. Las ropas escasas y viejas con las que ingresaban estos niños no dejaban lugar a dudas respecto a la clase social a la que pertenecían sus progenitoras.

115 PEÑA SANTOS, Antonio de la; JUEGA PUIG, Juan y LÓPEZ DE GUEREÑU POLÁN, Luis. Historia de Pontevedra, Vía Láctea, A Coruña, 1996. RODRÍGUEZ FIGUEIREDO, Modesto. Ayer de Pontevedra. Efemérides, A Coruña, Ediciós do Castro, 1992. FORTES BOUZÁN, Xosé. Historia de la Ciudad de Pontevedra, A Coruña, La Voz de Galicia, 1993. FORTES BOUZÁN, Xosé. Pontevedra en el espejo del tiempo, Pontevedra, Caixa Pontevedra, 1995. 
Otros asilados eran reclamados por mujeres que se ofrecían como nodrizas sin retribución. De algunas de ellas sabemos que eran las propias madres porque así lo declaraban. En otros casos, la presentación de una nota igual a la que portaba el niño en el momento de ser abandonado o la coincidencia de apellidos entre la aspirante a ama y el menor, nos hacen creer que eran las propias progenitoras las que recuperaban a sus hijos utilizando un método sencillo y que no requería apenas documentación.

Algunos acogidos, muy pocos, fueron prohijados. Todos ellos tenían entre seis y nueve años, es decir, una edad en la no necesitaban tanta dedicación y ya podían realizar algún pequeño servicio. Los prohijamientos los realizaban tanto personas casadas como solteras, al contrario de lo que ocurría en otras inclusas que dificultaban los solicitados por personas solas. En la Inclusa de Pontevedra, la inmensa mayoría de los prohijantes solteros eran mujeres. Ellas, y también los matrimonios, pertenecían a las capas humildes de la población, vivían en zonas rurales, eran casi todos analfabetos y efectuaron los prohijamientos a edades avanzadas, ya fuera porque entonces era cuando constataban la imposibilidad de engendrar un hijo, como porque empezaban a ver la necesidad de alguien que les cuidase en su vejez. Esto último creemos que es la explicación del hecho de que solamente se prohijara un varón y el resto fueran niñas.

Una gran parte de los asilados que no eran recuperados por sus padres ni eran prohijados, se quedaban viviendo con sus nodrizas, aún tras haber cumplido los siete años. Teniendo en cuenta que estas mujeres vivían en los municipios más deprimidos de las provincias de Pontevedra y Lugo, y que sólo las más necesitadas optaban por lactar a un inclusero, podemos concluir que a estos niños, que ya compartían la pobreza de sus amas, les esperaba un futuro lleno de penalidades.

En el caso de que un ama decidiera no quedarse el acogido a su cargo, al llegar a los siete años lo devolvía a la Inclusa y de allí era trasladado al Hospicio Provincial. La mayoría de los que ingresaron eran varones, y permanecían en esta Institución hasta la edad reglamentaria, dado que no solían ser prohijados.

Los expósitos de la Inclusa tenían, en algunas ocasiones, problemas de identidad propiciados por el secretismo que imperaba en los libros de registro, en la documentación a ellos referida y en la propia Institución. Algunos antiguos acogidos, ya adultos, no sabían exactamente cuál era su apellido ni su edad, y sólo llegaban a tener estos datos cuando se casaban y pedían su certificado de bautismo y de inscripción en el Registro Civil.

La Inclusa de Pontevedra no tenía papel alguno en la vida pública y en la prensa pontevedresa, a pesar de acoger y tener la tutela sobre un número importante de menores, y de que una parte apreciable de la población tuviera relación con esta Institución, como eran las madres que abandonaban a sus hijos, las viudas que solicitaban el ingreso de sus vástagos, las nodrizas internas y externas, y los prohijan- 
tes. Creemos que la Inclusa, y el resto de establecimientos benéficos similares, al estar ligados a la ilegitimidad, a la deshonra y a la pobreza, provocaban el rechazo social y el distanciamiento de las personas más destacadas de la Ciudad.
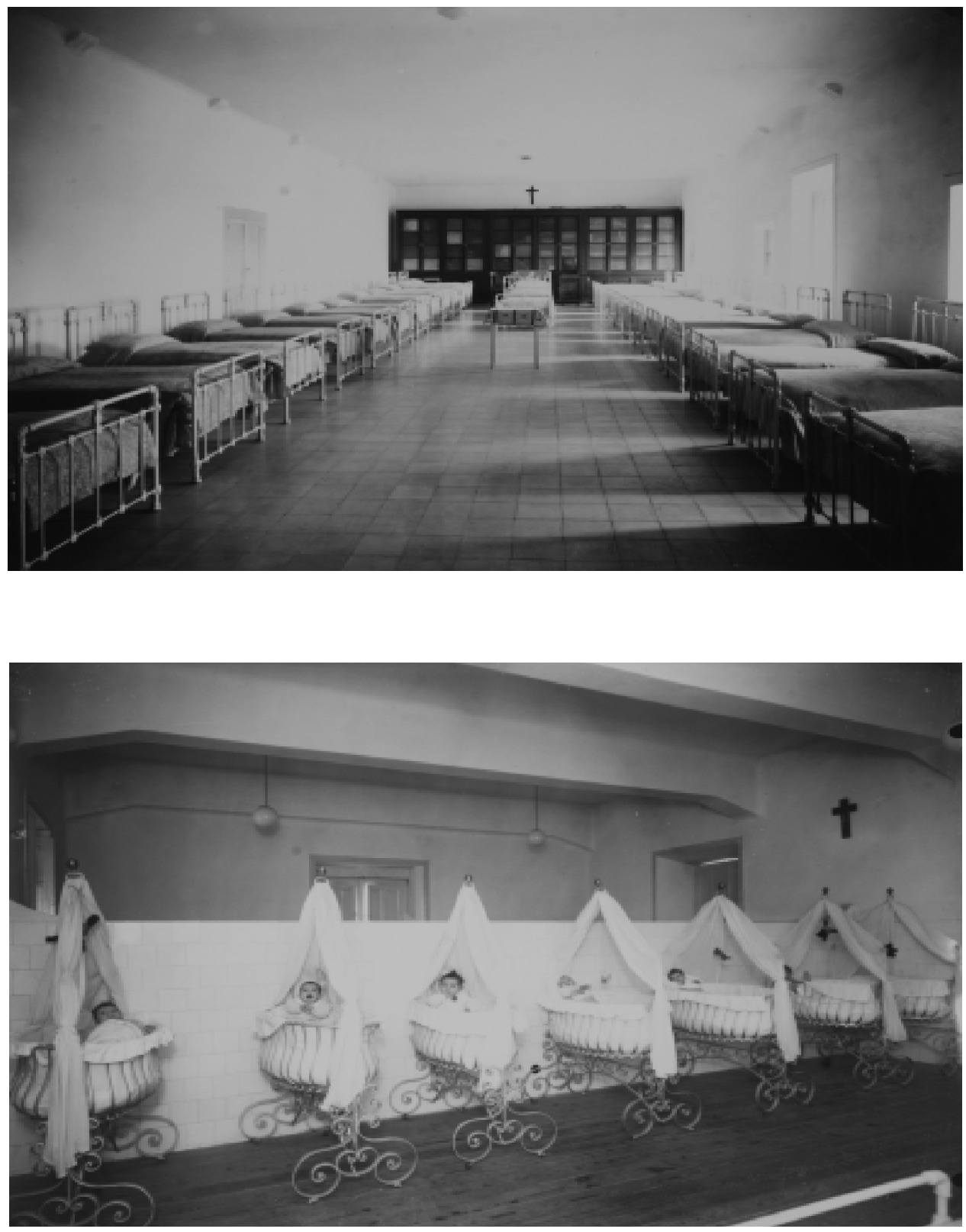


\section{FUENTES MANUSCRITAS}

ARCHIVO HISTÓRICO DE LA DIPUTACIÓN DE PONTEVEDRA

Fondo Especial n ${ }^{\circ}$ 15, Inclusa, libros no 15.207 y del 15.168 al 15.202. Además, leg. 940, 960, 964, 980, 981, 982, 983 у 993.

Sección Hospitales, leg. 435, 2.164, 2.165.

ARCHIVO HISTÓRICO DE LA DIPUTACIÓN DE BARCELONA

Sección de Beneficencia y Sanidad, legajos j-2.410, j-2.414, j-2.429 al j-2.434, j-2851 al j-2.885, j-3.017, j-3020 al j-3.022, j-3.029, j-3.061 al j-3112. Legajos 714, 772, C.C/VII 609 y C.C/VII 610.

\section{FUENTES IMPRESAS}

\section{ANUARIOS, ESTADÍSTICAS, MEMORIAS Y REGLAMENTOS}

Boletín mensual de estadística demográfica-sanitaria de la Península e islas adyacentes. Madrid, 1883.

Boletín Oficial de la Provincia de Pontevedra, 19-5-1906.

Código Civil de 1889.

El consultor. Nueva Guía de Barcelona, Barcelona, 1857.

Ley de Beneficencia del 20-6-1849.

Ley de Registro civil del 17-6-1890.

Real Orden, 15-3-1854 y 15-4-1854.

Reglamento de fecha 14-5-1852 para la ejecución de la Ley de Beneficencia de 20-6-1849.

Reglamento de la Casa de Maternidad y Espósitos de la Provincia de Lugo, Lugo, 1863.

Reglamento de la Casa Provincial de Maternidad y Expósitos de Barcelona, Barcelona, 1890.

Reglamento para el régimen interior administrativo y económico del establecimiento provincial de Espósitos de Málaga y sus hijuelas, Málaga, 1858.

Reglamento para el régimen interior del Real Hospital de Nuestra Señora de Gracia de Zaragoza, Zaragoza, 1861.

Reglamento para el régimen interior del Hospicio Provincial de Zaragoza, Zaragoza, 1883.

Reglamento para el régimen y gobierno del Gran Hospital de Santiago y de la Casa de Expósitos anexa al mismo, La Coruña, 1881.

Reglamentos de la Inclusa, Colegio de la Paz, Casa de Maternidad y Asilo para los hijos de las cigarreras, Madrid, 1888.

Reseña geográfica y estadística de España, Madrid, 1888. 
RULL, Juan y CABOT, José. Estudio demográfico-médico del quinquenio de 1883 a 1887 de la Casa Provincial de Maternidad y Expósitos de Barcelona, Barcelona, 1889.

\section{DIARIOS Y REVISTAS}

Crónica de Pontevedra, Pontevedra, no 158 y 365, del 9-11-1886 y 4-6-1887, respectivamente. .

El Anunciador, Pontevedra, no 1.385 y 4.709 al 4.719, del 20-9-1881, y del 20-10-1892 al 30-10-1892, respectivamente.

El Diario de Pontevedra, Pontevedra, $\mathrm{n}^{\circ} 5.300$ y 5.603, de fechas 28-1-1902 y 18-12-1902.

Revista de Beneficencia, Madrid, $\mathrm{n}^{\circ}$ 2, 5, 12,16 y 18, de fechas 22-8-1887, 15-9-1887, 8-11-1887, 812-1887 y 22-12-1887, respectivamente.

\section{LIBROS, ARTÍCULOS Y FOLLETOS DE LA ÉPOCA}

AGUIRRE BARRIO, Julián. Mortalidad en la primera infancia, sus causas y medios de atenuarlas, Madrid, 1885.

Actas del Congreso Médico Internacional de Sevilla, Sevilla, 1882.

ALBÓ MARTÍ, Ramón. La Caridad. Su acción y organización en Barcelona, Barcelona, 1901.

ARENAL, Concepción. La beneficencia, la filantropía y la caridad, Madrid, 1861.

_-.Pobres inocentes", en La Voz de la Caridad, de beneficencia y establecimientos penales, Madrid, $\mathrm{n}^{\mathrm{o}} 31,15-6-1871$.

—_Los niños pobres”, en El Diario de Pontevedra, Pontevedra, nº 5.610, 27-10-1902.

BOUSQUET, J. "Medios para combatir la mortalidad infantil”, en Gaceta Médica Catalana, Barcelona, t. XXVI, nº 616, 28-2-1903.

BROCHARD, M. La vérité sur les enfants trouvés, París, 1876.

FIGUEROLA, Laureano. Estadística de Barcelona en 1849, Barcelona, 1849. Reedición del Instituto de Estudios Fiscales, Madrid, 1968.

GRASSET, Vicente. "De los espósitos", en Acta de la sesión literaria pública que el día 2 de enero de 1851 celebró la Academia Nacional de Medicina y Cirugía de Barcelona, Barcelona, 1851.

HAUSER, Philippe. Madrid bajo el punto de vista médico-social, Madrid, 1902. Reedición a cargo de Carmen del Moral, Editora Nacional, Madrid, 1979.

HERNÁNDEZ IGLESIAS, Fermín. Tratado práctico de la Beneficencia particular, Madrid, 1874.

HEUBNER, O. "En el XIII congreso internacional de medicina, París 2-9 agosto 1900”, en La Medicina de los Niños, Barcelona, $\mathrm{n}^{\circ}$ 9, septiembre de 1900.

Manual de Beneficencia, Madrid, 1931.

MARTÍNEZ VARGAS, Andrés.’La protección a los niños”, en La Medicina de los niños, Barcelona, febrero de 1900.

TOLOSA LATOUR, M. Medicina e higiene de los niños, Madrid, 1893. 


\section{BIBLIOGRAFÍA}

ALBÓ MARTÍ, Ramón. Barcelona caritativa, benéfica y social, Barcelona, 1914.

ÁLVAREZ SANTALÓ, León Carlos. Marginación social y mentalidad en Andalucía Occidental: Expósitos en Sevilla (1613-1910), Junta de Andalucía, Sevilla, 1980.

ARBELO, Antonio. La mortalidad de la infancia en España, 1901-1950, Dirección General de Sanidad, Madrid, 1962.

BARREIRO FERNÁNDEZ, Xosé Ramón. Historia de Galicia, Gamma, A Coruña, 1984.

BEAUVALET-BOUTOURYE, Scarlett. Naître à l'hôpital au XX siècle, editorial Belín, París, 1999.

BORRÁS LLOP, José María. Historia de la infancia en la España contemporánea, 1834-1936, Ministerio de Trabajo y Asuntos Sociales, Madrid, 1996.

BRAVO FRÍAS, J. y ALONSO MUÑOYERRO, J.A. La transformación de las Inclusas, Madrid, 1924.

CÁMARA ÁLVAREZ, Manuel de la. Reflexiones sobre la filiación ilegítima en el Derecho Español, Tecnos, Madrid, 1975.

COMÍN, Jorge. El problema de las inclusas en España, Dirección General de Sanidad, Madrid, 1944.

DEMERSON, Paula de. "Catálogo de las socias de honor y mérito de la Junta de Damas Matritense, 1787-1811", en Anales del Instituto de Estudios Madrileños, Consejo Superior de Investigaciones Científicas, Madrid, 1971, t. VII.

DÍEZ RODRÍGUEZ, Fernando. La sociedad desasistida. El sistema benéfico asistencial en la Valencia del siglo XIX, Diputación de Valencia, Valencia, 1993.

DOPICO, Francisco. "Desarrollo económico-social y mortalidad infantil. Diferencias regionales (1900-1950)", en Crisis, autonomías y desarrollo regional. IX reunión de estudios regionales, Universidad de Santiago de Compostela, Santiago de Compostela, 1985.

FARIÑA JAMARDO, Xosé y PEREIRA FIGUEROA, Miguel. A Deputación de Pontevedra, 18361986, Diputación de Pontevedra, Pontevedra, 1986, pp. 354 y 366-8.

FERNÁNDEZ FERNÁNDEZ, José María. "La Casa Cuna de Mondoñedo”, en Estudios Mindonienses, Ferrol, n 12, 1996.

FERNÁNDEZ GARCÍA, Antonio. La enfermedad como indicador social. Consideraciones metodológicas", en CASTILLO, Santiago (coord.), La Historia Social en España. Actualidad y perspectivas, Siglo XXI, Madrid, 1991.

FONTANA LÁZARO, Josep. "Bastardos y ladrones", en Revista de Occidente, Madrid, no 45, febrero de 1985.

FORTES BOUZÁn, Xosé. Historia de la Ciudad de Pontevedra, A Coruña, La Voz de Galicia, 1993.

-Pontevedra en el espejo del tiempo, Pontevedra, Caixa Pontevedra, 1995.

FUENTES CABALLERO, $\mathrm{M}^{\mathrm{a}}$ Teresa. "Costumbres privadas e interés público. La lactancia materna en la literatura médica de divulgación. Barcelona 1880-90”, en Dynamis, vol. 16, Universidad de Granada, 1996. 
GALICIA PINTO, Isabel. La Real Casa Hospicio de Zamora. Asistencia social a marginados, 17981850, Diputación provincial de Zamora, Zamora, 1985.

GARNELO MARIÑAS, Elena. "La Inclusa provincial de Pontevedra, 1872-1894", en Pontevedra, Revista de Estudios Provinciales, Pontevedra, nº 4, 1988.

GÓMEZ-FERRER MORANT, Guadalupe. "La imagen de la mujer en la novela de la Restauración: ocio social y trabajo doméstico", en Mujer y sociedad en España, (1700-1975), Instituto de la Mujer, Madrid, 1986.

GÓMEZ SALVO, L. Las inclusas españolas. De sus defectos y del modo de corregirlos, Zaragoza, 1926.

GONZÁLEZ ÁLVAREZ, Baldomero. Tratado didáctico de enfermedades de los niños, Madrid, 1905.

GONZÁLEZ CANALEJO, Carmen. "Las nodrizas en Almería: ¿Oficio o rol biológico?”, en Actas del III Congreso de Historia de Andalucía, Cajasur, Córdoba, t. II, 2001.

GUARDIA, Carmen de la. "El gran despertar. Románticas y reformistas en Estados Unidos y España", en Historia Social, Valencia, n 31, 1998.

GUTIÉRREZ SÁNCHEZ, Mercedes. "Crisis social y asistencia pública en el último cuarto del siglo XIX”, en AA.VV. Historia de la acción social pública en España. Beneficencia y previsión, Ministerio de Trabajo y Seguridad Social, Madrid, 1990.

JUNCEDA AVELLO, Enrique. Historia del Real Hospicio y Hospital Real de la Ciudad de Oviedo, Instituto de Estudios Asturianos, Oviedo, 1984.

LAFFITE, María, (duquesa de Campo Alange). La mujer en España. Cien años de su historia, 18601960, Aguilar, Madrid, 1963.

LAPLAIGE, Danielle. Sans famille à París. Orphelins et enfants abandonnés de la Seine au XIX siècle, Centurion, París, 1989.

LÓPEZ-CORDÓN CORTEZO, María Victoria. "La situación de la mujer a finales del Antiguo Régimen (1760-1860)" en AA.VV. Mujer y sociedad en España (1700-1975), Ministerio de Cultura, Madrid, 1986.

LÓPEZ TABOADA, J. La población de Galicia, 1860-1991, Fundación Caixa Galicia, A Coruña, 1996.

MONTIEL PASTOR, Josep. "De la creación fins a la Mancomunitat, 1853-1924", en AA.VV. La Casa de Maternitat i Expòsits. Les Corts, Barcelona, 2004.

MORALES ÁLVAREZ, Ángel. Casa Cuna de Ponferrada, 1775-1937, Instituto de Estudios Bercianos, Ponferrada, 2001.

NADAL, Jordi. La población española, Ariel, Barcelona, 1984.

ONGER, Sergio. "Andrea Buffini e il dibattitto su "ruota" e infanzia abbandonata nella Lombardia dell'Ottocento", en AA.VV. Enfance abandonnée et société en Europe, XIV-XX siècle, École Française de Roma, Roma, 1991.

PEÑA SANTOS, Antonio de la; JUEGA PUIG, Juan y LÓPEZ DE GUEREÑU POLÁN, Luis. Historia de Pontevedra, Vía Láctea, A Coruña, 1996. 
PÉREZ FARIÑA, María Luisa. La ciudad de Pontevedra. Evolución histórica y demográfica, Universidad de Santiago de Compostela, Santiago de Compostela, 1985.

PÉREZ GARCÍA, José Manuel. "La mortalidad infantil en la Galicia del siglo XIX. El ejemplo de los expósitos del Hospital de los Reyes Católicos de Santiago", en Estudios Compostelanos, Santiago de Compostela, nº 4, 1976.

PERINAT, Adolfo y MARRADES, María Isabel. Mujer, prensa y sociedad en España. 1800-1939, Centro de Investigaciones Sociológicas, Madrid, 1980.

RODRÍGUEZ FIGUEIREDO, Modesto. Ayer de Pontevedra. Efemérides, A Coruña, Ediciós do Castro, 1992.

RODRÍGUEZ MARTÍN, Ana María. "Algúns aspectos relativos á Inclusa de Pontevedra, 1872-1903”, en Pontevedra. Revista de Estudios Provinciais, Pontevedra, n 16, Pontevedra, 2001.

—-"La Inclusa de Pontevedra”, en Pontevedra. Revista de Estudios Provinciais, n 19, Pontevedra, 2003.

ROMÁN PORTAS, Luz. La asistencia social en Galicia: el Hospicio de Pobres de Santiago de Compostela (1860-1900), Diputación Provincial de A Coruña, A Coruña, 1989.

SÁNCHEZ YÁÑEZ, Margarita. "Nenos expósitos de Ferrol”, Estudios Mindonienses, Ferrol, nº 12, 1996.

SEVILLA BUJALANCE, Juan Luis. Los niños expósitos y desamparados en nuestro Derecho histórico, Universidad de Córdoba, Córdoba, 2001.

SHORTER, Edward. Naissance de la famille moderne, Seuil, París, 1977.

ULTECIA CARDONA. C. "Mortalidad de la primera infancia", en AA.VV. Cuatro siglos de acción social. De la beneficencia al bienestar social, Siglo XXI, Madrid, 1986.

URIBE-ETXEBARRÍA FLORES, Arántzazu. Marginalidad protegida: mujeres y niños abandonados en Navarra 1890-1930, Universidad del País Vasco, Bilbao, 1996.

VALVERDE LAMSFUS, Lola. Entre el deshonor y la miseria. Infancia abandonada en Guipúzcoa y Navarra. Siglos XVIII y XIX, Universidad del País Vasco, Bilbao, 1994.

VIDAL GALACHE, Benicia y Florentina. "Porque Usía es condesa", en Espacio, tiempo y forma, serie V, Madrid, $\mathrm{n}^{\circ} 11,1988$.

-De princesas, señoras y otras clases de mujeres, ediciones de la UNED, Madrid, 1999. 